\title{
Understanding Meaningful Participation and the Situated Use of Technology in Community Music for Active Ageing
}

\author{
Mao Maoa*, Alan F. Blackwellb, David A. Gooda \\ aDepartment of Psychology, University of Cambridge, Cambridge, United Kingdom; \\ ${ }_{b}$ Computer Laboratory, University of Cambridge, Cambridge, United Kingdom
}

*Corresponding author: Email: m.mao@cantab.net

\begin{abstract}
An unfortunate tendency in previous HCI research has been to give the impression that it aims to "fix the problem" of human ageing, suggesting a "deficit" model of ageing or a "prosthetic" model of technology. We conducted diary-aided interviews to investigate how technology use is situated in active, healthy older adults' meaningful participation in community music. We argue that recognising community music practices and technology use as situated action provides opportunities to grasp the subtleties of social participation and design for active ageing. We identified technology-mediated music practices, such as music sharing and revisiting, and how they evolved through the reconfiguration of connections between technology, competence, and forward-facing identities. We found that identity development, via routes such as exercising control, role transitions and social spaces, had psychological significance and implications for active ageing. We explore how $\mathrm{HCI}$ leverages the perspective of active ageing and might facilitate older adults' meaningful participation enhanced by technologies.
\end{abstract}

\section{Research Highlights:}

1. This paper challenges the "deficit" model of ageing and the "prosthetic" model of technology. 
2. Recognising community music practices and technology use as situated actions illuminates the complexities of meaningful participation and the ways in which technology coordinates the practices.

3. Technology-mediated practices evolve through the reconfiguration of connections between technological devices, competence, meanings, and forwardfacing identities.

4. Identity development, via routes such as exercising control, role transition, and social spaces, has psychological significance.

Keywords: Active ageing; older adults; participation; community music; technology use; situated action

\section{Introduction}

HCI research in relation to ageing often sets out to "fix the problem" of ageing in some way, which suggests both a "deficit" model of ageing and also a "prosthetic" model of technology. Even when advocating active and healthy ageing, technology designers may inadvertently shift toward a deficit model in search of a simple problem to be "fixed". As useful outcomes of such research, assistive technologies have been developed to provide solutions for the older population experiencing age-related decline in their physical, cognitive, or social capabilities (Vines et al., 2015). Such technologies include systems that prevent older people from falling, remote communication tools in support of contacting their children and grandchildren, patient-caregiver/relatives communication, and multimedia tools in support of dementia care (see Righi, Sayago, \& Blat, 2017; Vines et al., 2015). On the other hand, as a consequence of "prosthetic imagination", technical solutions may emphasise a standardised or universal expectation of human life, being designed to compensate for a perceived lack of "normal" human capabilities (Blackwell, 2010; Ferrario et al., 2017). For example, tools that help provoke memory and reminiscence have been overtly developed to compensate for 
dementia, and those with a "prosthetic" view of technology tend to replace the missing capability caused by dementia rather than supporting existing capabilities (Alm et al., 2003; Piper et al., 2013; Riley et al., 2009). Prosthetic systems may not be appropriate for healthy and active older people and may even isolate or stigmatise them.

Active ageing challenges the "deficit" model of ageing and the "prosthetic" model in HCI, because people who are actively ageing have healthy lives, with nothing clearly to be "fixed". The policy framework for active ageing advocates activities and programmes for social engagement, personal development, and even societal change (World Health Organization, 2002). Active ageing research highlights the understanding of participation, one of the three building blocks (i.e., participation, health, and security) in the WHO's policy framework of active ageing. Though often associated with maintaining social bonding, staying healthy, and keeping active (Adams et al., 2011; Stenner et al., 2011; Stephens et al., 2011), being "active" does not solely refer to being physically active or capable of contributing to the workforce (Boudiny, 2013). Researchers frame active ageing as the experience of continued growth and participation in family, social, and community activities (Bowling, 2008), and claim that older people are able to make active contributions to their health and well-being through participation (Stenner, McFarquhar, \& Bowling, 2011). Moreover, active ageing researchers have been exploring how people spend and should spend their time on social participation, so as to maintain healthy, active and secure lives. However, it is challenging to define what "active" means to older people themselves without attending to why and how people experience their later lives in their particular ways (Bowling, 2008; Clarke \& Warren, 2007; Stenner et al., 2011). Boudiny (2013) suggests that meaningfulness refers to the meanings that older adults attach to what they do. This strand of thought further requires a situated understanding of the meanings and 
subtleties of participation, which is less addressed in ageing literature (Adams et al., 2011).

There is also a challenge for HCI research to understand the particularity of technology use outside the presumption that we are fixing a problem. Echoing the idea of active ageing, HCI researchers recently suggest more active ways to reconfigure old age and are beginning to consider the heterogeneous nature of ageing (Lazar \& Nguyen, 2017; Vines et al., 2012) when designing technologies (e.g., Brewer \& Piper, 2016; Morreale, Moro, Chamberlain, Benford, \& McPherson, 2017; Morrissey et al., 2017). Digital solutions for older adults recently demonstrate a shift from focusing on addressing problems due to ageing-related deficits to understanding older adults as competent and motivated actors in maintaining healthy and active lives through social participation (e.g., Vines, Pritchard, Wright, Olivier, \& Brittain, 2015). This paper does not regard ageing as a problem, is not setting out to solve a problem, but to understand how technology becomes a part of the lives of people who don't have problems. We adopt Lucy Suchman's notion of "situated action" in the context of HCI to understand the role that technology plays in contextual and social settings surrounding older people's everyday practices of community music. A central tenet of "situated action" is that "every course of action depends in essential ways on its material and social circumstances" (Suchman, 2007, p. 70). This line of work reconstructs technology use as situated, social practices: "technologies are constituted through and inseparable from the specifically situated practices of their use" (Suchman et al., 1999, p. 399). This perspective sheds light on the subtleties of social participation and the mundane nature of daily routines in later life (Comber et al., 2013; Kuutti \& Bannon, 2014), by depicting who participates, how, where and when they participate, the values and 
meanings that are bound up with participation, as well as the contexts in which "doing" occurs (Shove, 2007).

We are also interested in why older people participate and the meanings they attach to what they do - their social participation and situated technology use. The growing body of work on the active-ageing discourse has focused on the subjective meanings and situated experiences of active participation to inform why and how older adults experience their lives in their particular ways (Boudiny, 2013; Bowling, 2008; Clarke \& Warren, 2007; Stenner et al., 2011). One way of attending to the subjective meanings is to examine how one's sense of self and social identity develop through participation. Social identification with groups structures people's perception and actions (Reicher \& Hopkins, 2016). One strand of thought suggests that the image of a group emerges and grow as people participate. An individual's knowledge, values, and emotions of belonging to certain social groups accumulate with such images (Tajfel, 2010; Tajfel \& Turner, 2004), and may be further constituted through the constant interaction with others (Marwick \& Boyd, 2011). Another line of research adopts a selfcategorisation approach (Turner et al., 1987), suggesting that the processes of social identification are future-oriented and dynamic (Reicher \& Hopkins, 2016). Futureoriented selves guide actions in people's lives by organising future-oriented behaviour and contributing to the ability to conduct possible actions (Markus \& Nurius, 1986). Examples of identity, such as musical possible selves in (Creech, Hallam, Varvarigou, Gaunt, McQueen, \& Pincas, 2014) and a sense of belonging (Brewer \& Piper, 2016), have been emphasised in active ageing literature. Another psychological construct to unpack the meanings of participation is self-efficacy, which refers to the judgement of one's capability to perform a given task. Active ageing involves "competence-thinking" with an emphasis on older adults' competence and knowledge (as cited in Boudiny, 
2013). Likewise, psychological studies argue that it is essential to acquire skills and obtain a sense of control to alter efficacy expectations, so as to deal with challenges in later life (e.g., Mun \& Hwang, 2003). Meanings are interdependent on what people do and have. To this end, examining social identities and self-efficacy from psychology and social practice perspectives may add to the active ageing literature on how the situated experiences and motivations of participation are represented and communicated within the system of self.

The contribution of this research is therefore to understand how technology is used within a context of healthy living and active ageing, producing an understanding that is not reliant on the interests and priorities presumed by younger users (especially those within the life periods when either professional employment or family are their primary activities). This study is motivated by exploratory inquiry into the role that technology plays as part of meaningful participation in community music, and any tensions that might arise. Community music was chosen as an exemplar of the many forms of social participation (see Bukov, Maas, \& Lampert, 2002) in old age for two reasons: First, our location in Eastern England is known for its unique music culture and an unusually large population of local musicians (Mao et al., 2016). Our prior ethnographic inspired study shows that this population is mainly later mid-aged and older, stably attends community music on a regular basis, and uses a range of physical music possessions and digital music technologies1 such as PCs, MP3s, music streaming services and cloud storage applications (Mao et al., 2016). Community music practitioners are also interested in benefiting from cloud and streaming technologies in

1 Unless specifically stated, "digital music technologies" in this study, according to Krause and North (2014)'s definition, refers to "technology, application, and devices that allow users to interact with music digitally". 
support of community music practices (Doebele, 2012; O'Flynn, 2015). As such, it is constructive to study the situated use of technology in relation to community music participation among this population. Second, group singing, as a "universal human behaviour" (Pearce et al., 2015), provides "social spaces" (Taylor et al., 2016) for active engaging, learning and socialising among older people. Our prior ethnographic inspired study (Mao et al., 2016) confirms this with evidence from both informal music groups (i.e., music workshops, short-term music classes, music festivals and events) and formal music groups (i.e., orchestras and choirs). To this end, we assumed that an investigation with community music participants may shed light on active ageing in similar "social spaces" more generally. To understand the particularity of technology use and the development of self and social identity among active and healthy older adults, we ask the following research questions:

- RQ1: What is the situated use of technology for meaningful participation in community music?

- RQ2: How is identity development associated with the situated use of technology?

\section{Literature Review}

\section{Active Ageing, Social Participation and Identity Development}

Active ageing is defined as "the process of optimising opportunities for health, participation and security in order to enhance quality of life as people age" (World Health Organization, 2002, p. 12). Researchers argue that the essence of active ageing is the understanding of activity and participation (Walker, 2002), which helps to correct the bias implied if "successful ageing" excludes frail and disabled older people (Bowling \& Iliffe, 2006; Rozanova, 2010), and ensures that the specificities of lived 
experience of older people are recognised in research and policy (Holstein \& Minkler, 2007; Stenner et al., 2011; Walker, 2002). In later life, older people often strive for the accomplishment of everyday activities and ordinary needs (e.g., "living for now", "taking a day at a time") instead of pursuing ambitious goals (Clarke \& Warren, 2007). This finding further implies the importance of attending to subtler understanding (Clarke \& Warren, 2007) and "lay models" (Stenner et al., 2011) of active ageing, and the prevalence of forward-facing perceptions in older age through participation in ordinary activities (Bowling, 2008; Stenner et al., 2011).

One body of work has investigated the benefits and types of active participation. Social participation has a range of health benefits via psychological pathways such as self-efficacy and competence (e.g., agentic capacity in Stenner et al., 2011), coping effectiveness in terms of social and health changes (Bukov et al., 2002; Ouwehand et al., 2007), and the maintenance of social and psychological resources (Cramm et al., 2013). Although separately characterised, aspects of participation in social activities, health, well-being and life satisfaction are interdependent on each other in a complex manner (Adams et al., 2011). This body of work has been advanced by the recognised necessity of considering different types (e.g., goals, content, context) of activities (see Bukov et al., 2002) and individual factors in relation to participation, since not all activities are equally valued by all older adults (Adams et al., 2011). Bukov et al. (2002) define social participation in terms of the socially-oriented sharing of resources and argue that there is a hierarchical, accumulative relationship among different levels of commitment of participation (i.e., collective, productive and political participation). More specifically, older people who take part in more demanding social participation (e.g., political participation) can participate in less demanding activities (e.g., collective or productive participation) as well. The cumulative nature of participation is the 
supplement to the selection hypothesis of ageing (e.g., Carstensen's socioemotional selectivity theory). Research suggests that older people participate in more than one type of social activities (e.g., Adams et al., 2011), whilst it is also noted that the quality of activities is no less important than the quantity and range of activities (e.g., Gibson, 1987).

Much of the above suggests that it is essential to understand how older people experience participation, especially in terms of the meanings and values that are enacted through participation, as noted in the Introduction. Sugarhood et al. (2017) conceptualise social participation as an adaptive process, in which values (e.g., connectedness, autonomy, affirmation, maintaining self-identity) are enacted, and choices are guided by the enacted values. In the case of community music participation, Creech, Varvarigou, Hallam, et al. (2014) identify critical practices of community music (i.e., scaffolding, modelling, giving and receiving feedback) that facilitate identity navigation and reinforce interpersonal relationship. Bailey and Davidson (2002) conceptualise group singing as adaptive and identify four categories of benefits proximate to health benefits: clinical-type benefits, audience-choir reciprocity, benefits associated with the group process, and benefits in relation to mental engagement. Positive psychology literature, although still under debate, has been arguing that “experiencing life as meaningful” is a significant component of psychological wellbeing (de Muijnck, 2013; Seligman, 2012). To this end, the consideration of the meanings of participation provides a lens, through which we could draw a nuanced picture of active music participation and its connection to psychological well-being.

Research has shown that social activities (including arts and music activities) provide people with many ways of understanding the purposes and meanings of their lives (Csikszentmihalyi, 2013; Seligman, 2012) and help them develop their identities 
(e.g., Crescioni \& Baumeister, 2013; Hays \& Minichiello, 2005). Specifically in the context of communal music, people not only use music as a "symbol" to define their self-identities (Hays, 2005), but also experience a sense of belonging and connectedness to like-minded others through participation (e.g., Hallam et al., 2012a; Packer \& Ballantyne, 2011). Also, people obtain essential material and psychological resources (DeNora, 2000) that further support their defining, changing, developing and constituting of their self and social identities (see a review by Croom, 2015). Bailey and Davidson (2002) conceptualise group singing as adaptive, and identify four categories of benefit: clinical-type benefits, audience-choir reciprocity, benefits associated with group process and benefits in relation to mental engagement. In a study with older people participating in community music, Creech et al. (2014) identify key practices of community music (i.e., scaffolding, modelling, giving and receiving feedback) that contribute to identity navigation and the reinforcement of interpersonal relationships. In particular, they argue that musical possible selves may contribute to subjective wellbeing by helping older people navigate the process of ageing, rendering enhanced senses of autonomy, purpose and social affirmation (Creech et al., 2014). Factors such as innovativeness and self-efficacy may influence the formation of music identity as well (Krause \& North, 2014). In line with active ageing research, having an appropriate perception of the self (Kroger \& McLean, 2011), formulating, constructing and maintaining social cohesion (Pearce et al., 2015) and a sense of autonomy and social affirmation (Creech et al., 2014) are essential for coping with social and health changes in old age. Although the angle of identity development helps advance research into the meanings of active participation in later life, it is still unclear how experiences and meanings of active participation are represented and communicated in the situated use of technology and the broader framework of active ageing. To this end, a better 
understanding of community music participation and the situated use of technology via the lens of identity development is needed.

\section{A working definition of meaningful participation}

Following the active-ageing discourse alongside our prior ethnographic inspired study (Mao et al., 2016), throughout the whole paper, we use the term "meaningful participation" to refer to the participation in music-related practices, either personal or social, individual or group-related, traditional or "youthful", that are evaluated as emotionally and personally meaningful in older people's everyday lives and are able to be regarded as indicators of their involvement with life (Boudiny, 2013; Carstensen et al., 1999; Hornung et al., 2017).

\section{Related Work}

Here we expand on HCI research that has begun to examine the situated use of technology in relation to active participation and ageing, outside the presumption that technology is designed to fix a problem. A common theme emerging from literature is the "practice" perspective (Kuutti \& Bannon, 2014) in which possessions and technological devices that people "have" are understood to be contingent on what they "do" (Comber et al., 2013; Shove, 2007), and in which practices are to be understood with reference to the time, place and concrete contexts where they take place (Kuutti \& Bannon, 2014). Although technology per se does not lie in the centre of social participation that occurs locally or face-to-face, the need of using various technological devices to sustain local events, facilitate socialisation, and help with adaptation to new environments is evident. For example, Lindley and Wallace (2015) note the importance of "honouring cherished possessions" as older people are faced with the situation of moving to care homes. Their work calls attention to the interaction with technologies 
and possessions beyond the domestic context (e.g., Kirk \& Sellen, 2010; Odom et al., 2012) and among older people in particular. A similarly notable category of activities is concerned with crafting and DIY (do-it-yourself). Technologies (i.e., hardware, software and materials for crafting) play a role in reflecting personal values and perceptions of ageing that are closely tied to the historical and cultural values (i.e., Sun, Lindtner, Ding, Lu, \& Gu, 2015), not to mention the role in sustaining community engagement and the making culture. Meanings of crafting echo that of other activities, such as building a sense of community, maintaining social connectedness, a sense of accomplishment and self-worth (Buehler et al., 2015; Rosner, 2016; Taylor et al., 2017, 2016). The health benefits of these activities are implicit in one of the cases in Taylor et al.'s study (2016): The Men's Shed group put mental health of retired men as the central focus of their making practices, such that making itself becomes a secondary value. Some researchers extend the significance of DIY practices by reframing old age in terms of wisdom, and empowering older people by supporting the artful integration (Suchman, 2002) of new technologies and everyday practices. For example, Rogers et al. (2014) found that MaKey MaKey toolkits can enable older people to combine their existing know-how with kit skills and to be involved in creative design activities by reflecting on how future technologies could be designed for children in a creative and mindful way. This resonates with the broader concept of active ageing and Vines et al.'s call (2015): the older population is heterogeneous, in the sense that different levels of skills and various situated needs co-exist.

A substantial vein of HCI research concerns older adults' social participation online: blogging (Brewer \& Piper, 2016; Lazar, Diaz, et al., 2017), completing crowdsourcing tasks (Brewer et al., 2016; Kobayashi et al., 2015), learning programming languages (Guo, 2017), seeking and sharing information in online health 
communities (Caldeira et al., 2017; Massimi et al., 2012; McNeill et al., 2017). These studies pay special attention to meanings such as the development of identity, selfexpression, self-achievement and group engagement (e.g., Brewer et al., 2016a, 2016b; Kobayashi et al., 2015). Technology in these studies stands in the centre of participation, through which people share knowledge via "storytelling" and construct their identities by incorporating technologies into their social lives (Suchman et al., 1999). In particular, technological skills and efficacy, concerns of privacy, accessibility issues, perceived usefulness, identity management online, and the reflection on personal and societal values via technology use have been explicitly mentioned in these studies. For example, in terms of efficacy and confidence, researchers argue that older people's prior life experiences and wisdom should be highlighted in social participation, so as to empower them with a feeling of confidence and reciprocity, and with self-worth from benefiting younger people (Hope et al., 2014; Rice et al., 2013). In terms of the tensions between privacy and information sharing, Light et al. (2017) suggest an indirect way of recommending local events to people living in an English town (e.g., things happening in their local areas rather than who is at the scene), so as to serve their information needs as well as protect their privacy. What can be implied here is that experiences, competences and tensions in relation to technology use and active participation need to be discussed alongside situated practices, social relations and the wider contexts. It echoes Suchman's "situated action" viewpoint that rather than fixing the machines per $s e$, it is more essential to fix the relationship between human and machines when dealing with machine misbehaviour (Suchman et al., 1999).

Music sharing, as a practice that is "richly linked to other social activities" (Brown et al., 2001, p. 179), covers a variety of topics in HCI literature: adoption, privacy, impression management, intimacy and the discovery of new music. When 
music and related devices go digital, sharing becomes complex and dynamic. As such, HCI work suggests technological design in support of multiple identities of users (Brown et al., 2001; Voida et al., 2006) and different levels of intimacy (Sease \& McDonald, 2009). Moreover, social media is gaining attention among musicians and community music practitioners. Shklovski et al. (2008), in a longitudinal study of musicians in the aftermath of Hurricane Katrina in New Orleans, find that musicians adopt and adapt computer-mediated communication and information seeking tools for personal and community use (e.g., maintaining the connection with their prior local communities after moving away from New Orleans). Hoare et al. (2014) argue that amateur musicians heavily rely on online tools and social media for scheduling their promotional activities.

Unsurprisingly, only a few HCI studies on dementia care are concerned with music-related activities among older adults (i.e., Lazar, Edasis, \& Piper, 2017; Morrissey, Wood, Green, Pantidi, \& McCarthy, 2016). In these studies, music is claimed to support the expression of the self, emotional regulation, as well as memory. Technological tools discussed in such studies mainly sustain music sessions and communication. However, relatively little is known about how and why older people participate in group music-making activities and why they use technology in their situated ways. Therefore, in this present study, we focus on understanding older participants' situated use of technology in the context of active participation in community music.

\section{Method}

\section{Diary-aided Interview}

Our proposed situated technology use calls for a methodology that is sensitive to the 
subjective, lived experiences of participation and the individual and social settings surrounding it. To this end, diary-aided interviews were conducted to explore meaningful participation and technology use. Thirty-three people signed up for the study and completed the screening questionnaire, after which 13 people completed the diary. Eventually, 11 of these participated in the diary-aided interview: 3 men and 8 women with ages ranging from 50 to 71, from Eastern England. They had been recruited via connections of the research team, distribution of posters and flyers, and the mailing lists of local community choirs. At the end of the interview, participants were thanked and given a CD of choral music for taking part. Prior to diary-aided interviews, the first author built rapport with participants via in-person meetings, and in many cases joining the group rehearsals and singing with them for one or two weeks. During the first six days, we asked participants to write down their "notable music moments" three times a day - in the morning, in the afternoon, and in the evening. For each time point, participants were asked to indicate what technology has been used, what tasks they have performed (e.g., details of music and events), and the context in which the notable music moments were taken (e.g., when, where, and with whom this moment takes place). Data drawn from these diary logs was used to understand how community music activities occurred in terms of time, device, and contexts. 


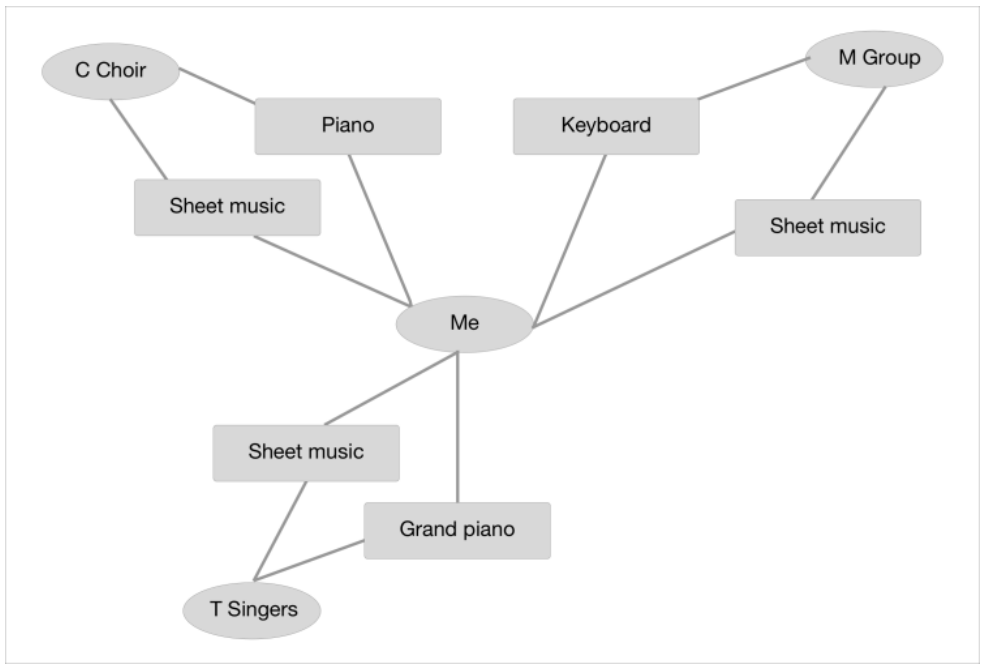

Figure 1. A reproduced social diagram from one participant

Beyond analysing diary logs, we wished to capture participants' mental model of their relationship with the inter-connected technologies and possessions in relation to music. The task on the seventh day was a drawing task, in which the participants were asked to draw a "social diagram" regarding all their social connections for music, and in what way they were connected. Here participants may write down the names of their connections in the choir, family, and acquaintances. For example, Figure 1 shows a reproduced social diagram drawn by a participant attending community music. This participant wrote "Me" in the centre of the diagram and connected herself with communities that she was in via musical instruments and sheet music. Some participants wrote or drew music-related technologies such as radio, laptops, and MP3s that were used for maintaining their social network of music.

Participants who completed the diary study were then invited to the research lab for a 60-min semi-structured interview on their experience of community music participation, and how they use, appropriate and perceive digital music technologies and information technologies in general. The first author conducted all the interviews. Participants were first asked to explain their social diagrams and the reasons behind 
them. We asked who the people or organisations were, how the mentioned technologies were used, and how the diagram developed over time. The first author also used diary data on "notable music moments" to prompt participants to talk about their meaningful music practices in detail. The participants were encouraged to talk about how they manipulated and experienced music in offline settings (such as radios, vinyl, and CDs) and to compare these experiences with their use of digital music technologies. Participants' life course experience (e.g., retirement, growing old, other significant life events in later midlife and old age) were explored during the interview. We also examined "extraordinary socio-technical events" (e.g., a newly acquired technical device, joining/leaving a community group) during the interview, to get a fresh perspective of participants' situations. All interviews were conducted in person and audio-recorded.

Table 1 An overview of data

\begin{tabular}{|c|c|c|c|}
\hline Category & Data element & Description & $\begin{array}{l}\text { Connection to } \\
\text { other data }\end{array}$ \\
\hline Diary & $\begin{array}{l}\text { Notable music } \\
\text { moments }\end{array}$ & $\begin{array}{l}\text { Contextual information on music } \\
\text { activities in terms of time, space, } \\
\text { devices, etc. } \\
\text { (Example entries) } \\
\text { - Task: listened to recordings of } \\
\text { Gerhard Husch, singing Brahms \& } \\
\text { Schubert; - Time: evening March } \\
\text { 19th; } \\
\text { - Technology: Sonos } \\
\text { - Context: considering recital C } \\
\text { pianist in college } \\
\text { The mental model of participants' } \\
\text { relationship with the inter- } \\
\text { connected technologies and } \\
\text { possessions in relation to music } \\
\text { (see Figure 1) }\end{array}$ & $\begin{array}{l}\text { To prompt } \\
\text { participants } \\
\text { reflection on } \\
\text { participation and } \\
\text { technology use }\end{array}$ \\
\hline
\end{tabular}




\begin{tabular}{llll}
\hline Category & Data element & Description & $\begin{array}{l}\text { Connection to } \\
\text { other data }\end{array}$ \\
\hline & - Music practices & $\begin{array}{l}\text { Subjective experience on the } \\
\text { practices related to community } \\
\text { - Use of }\end{array}$ & $\begin{array}{l}\text { Triangulation of } \\
\text { diary data }\end{array}$ \\
technology & $\begin{array}{l}\text { music, use and perception of } \\
\text { music and other Internet-based }\end{array}$ & \\
Interview & - Life-course \\
experience & technologies & \\
- Extraordinary & & \\
socio-technical & & \\
events & & \\
\hline
\end{tabular}

\section{Participants}

The interview participants had diverse backgrounds of employment status: in employment, semi-retired (taking on one or several part-time jobs while being retired from a full-time job), and fully retired (from one month to ten years). Almost all retired participants left their full-time jobs around the age of 60 and/or started part-time or voluntary jobs afterwards. A detailed description of years of retirement/semi-retirement is provided in Table 1. Among all the participants, P05 and P10 regarded themselves as "retired" when filling the screening questionnaire. However, during the interview, they indicated explicitly that they were actively participating in part-time work and actually regarded themselves as "semi-retired". From Table 1 we also noted that age and whether a participant is retired or semi-retired is not correlated. A 61-year-old participant was retired but a 71-year-old was still semi-retired.

Our participants had diverse educational backgrounds and jobs (including music-related as well as unrelated jobs). Two of them had the experience of leading a choir, teaching and conducting music. Recruiting both community music leaders/conductors and members gave us insights into the diverse strata of this community, and how digital music technologies were used and perceived in different contexts. Importantly, six of them had used some types of digital music services (e.g., 
BBC iPlayer, iTunes, SoundCloud, Spotify). The other five were asked to experiment with such services during the interview in order to capture their initial reactions.

Table 2 Demographics of diary-aided interview participants

\begin{tabular}{|c|c|c|c|c|}
\hline P\# & Age & $\begin{array}{l}\text { Employment } \\
\text { status }\end{array}$ & Music experiences & Employment experiences \\
\hline 01 & $\mathrm{M}(64)$ & Semi-retired & $\begin{array}{l}\text { Singing in a local } \\
\text { informal choir, attending } \\
\text { workshops sometimes }\end{array}$ & Doing part-time work \\
\hline 02 & $\mathrm{~F}(61)$ & Retired & $\begin{array}{l}\text { Participating in one } \\
\text { informal choir and a } \\
\text { formal choir, attending } \\
\text { workshops sometimes }\end{array}$ & \\
\hline 03 & $\mathrm{~F}(67)$ & Retired & $\begin{array}{l}\text { Singing in two informal } \\
\text { choirs and one formal } \\
\text { choir, used to be a } \\
\text { teaching assistant of } \\
\text { music classes }\end{array}$ & $\begin{array}{l}\text { Retired } 5 \text { years ago. Should } \\
\text { have retired at the age of } 60 \text {, } \\
\text { but postponed it because her } \\
\text { husband was still working }\end{array}$ \\
\hline 04 & $\mathrm{~F}(71)$ & Retired & $\begin{array}{l}\text { Singing in a formal } \\
\text { choir, used to be the } \\
\text { head of music in a } \\
\text { primary school }\end{array}$ & $\begin{array}{l}\text { Retired } 11 \text { years ago. Before } \\
\text { retirement, the music she did } \\
\text { was rarely dependent upon } \\
\text { technology. }\end{array}$ \\
\hline 05 & $\mathrm{M}(66)$ & $\begin{array}{l}\text { Retired } \\
\text { /semi-retired }\end{array}$ & $\begin{array}{l}\text { Singing in four formal } \\
\text { choirs }\end{array}$ & $\begin{array}{l}\text { Retired } 1 \text { month ago, but was } \\
\text { still doing some teaching }\end{array}$ \\
\hline 06 & $\mathrm{~F}(71)$ & Semi-retired & $\begin{array}{l}\text { Singing in five formal } \\
\text { choirs, singing as soloist } \\
\text { in two choirs, violin } \\
\text { player }\end{array}$ & $\begin{array}{l}\text { Still teaching and doing } \\
\text { research in a university. }\end{array}$ \\
\hline 07 & $\mathrm{~F}(62)$ & Semi-retired & $\begin{array}{l}\text { Singing in one informal } \\
\text { choir }\end{array}$ & $\begin{array}{l}\text { Regarded herself not retired } \\
\text { as she worked more than } \\
\text { before: having been working } \\
\text { with the school and teacher } \\
\text { association for years; recently } \\
\text { working for education scheme } \\
\text { in the summer. }\end{array}$ \\
\hline
\end{tabular}




\begin{tabular}{|c|c|c|c|c|}
\hline P\# & Age & $\begin{array}{l}\text { Employment } \\
\text { status }\end{array}$ & Music experiences & Employment experiences \\
\hline 08 & $\mathrm{M}(71)$ & Retired & $\begin{array}{l}\text { Previous church } \\
\text { musician, choir singer in } \\
\text { one formal choir, } \\
\text { attending workshops } \\
\text { sometimes }\end{array}$ & $\begin{array}{l}\text { Took a year off for a MA } \\
\text { degree at the age of } 50 \text { to } \\
\text { learn new things and how to } \\
\text { use the computer. Started a } \\
\text { company after retiring from } \\
\text { the church at the age of } 59 \\
\text { and worked full-time for eight } \\
\text { years. Then generally stopped } \\
\text { working for the company at } \\
\text { the age of } 67 \text {. }\end{array}$ \\
\hline 09 & $\mathrm{~F}(67)$ & Retired & $\begin{array}{l}\text { Singing in two formal } \\
\text { choirs }\end{array}$ & $\begin{array}{l}\text { Fully engaged in retirement } \\
\text { activities after retirement, } \\
\text { almost being occupied from } \\
\text { Monday to Friday. }\end{array}$ \\
\hline 10 & $F(69)$ & $\begin{array}{l}\text { Retired/semi- } \\
\text { retired }\end{array}$ & $\begin{array}{l}\text { Previously sang in seven } \\
\text { formal choirs, mainly } \\
\text { attending one currently }\end{array}$ & $\begin{array}{l}\text { Regarded herself as semi- } \\
\text { retired, as she still did part- } \\
\text { time work when she needed } \\
\text { to. }\end{array}$ \\
\hline 11 & $\mathrm{~F}(50)$ & Not retired & $\begin{array}{l}\text { Community music } \\
\text { instructor, composer, } \\
\text { and conductor }\end{array}$ & $\begin{array}{l}\text { A community music } \\
\text { practitioner. Fully engaged in } \\
\text { music teaching and } \\
\text { administrative work of music } \\
\text { groups }\end{array}$ \\
\hline
\end{tabular}

Analysis

All the diary entries were coded and classified into recurring categories that were derived from reading over participants' entries. An overview of diary entries revealed that conventional music listening devices, instruments, and technological devices in relation to music were prevalent among the diary entries. In addition, the time for using different music technologies was associated with different community music practices. The temporal distribution of the frequency of using music devices and community music practices were analysed and plotted (see Figure 2). For each of the statistics, figures were calculated for each participant by day of the week. Frequency data was further collapsed across days to draw an overall picture of how participants use different types of devices to perform different tasks at different time points each day. Figure 2 shows the distribution of device use and typical community music practices across six 
days among all participants. For the use of the radio, nearly every participant reported using radio for music listening every day. Perhaps more interestingly, more participants tended to use the radio in the morning or in the evening (see Figure 2-a, marked in blue). Music players and personal computers were used almost daily among our participants. In terms of activity types, singing and rehearsal (the frequency of which was $36 \%$ ) occurred every day (see Figure 2-b), followed by listening to music (27\%), performance (22\%), and practicing by oneself $(15 \%)$. This indicated that the majority of notable music moments were around community music participation. We examined the relationship between device use and community music activities. We found significant correlations between performance and the frequency of using laptops/streaming services $(r=.56, p<.05)$ and the frequency of using mobile phones $(r=-.64, p<.01)$. The frequency of rehearsal was positively correlated with the frequency of using laptops/streaming services $(r=.58, p<.05)$ and negatively correlated with the frequency of using mobile phones $(r=-.48, p<.05)$. 
(a)

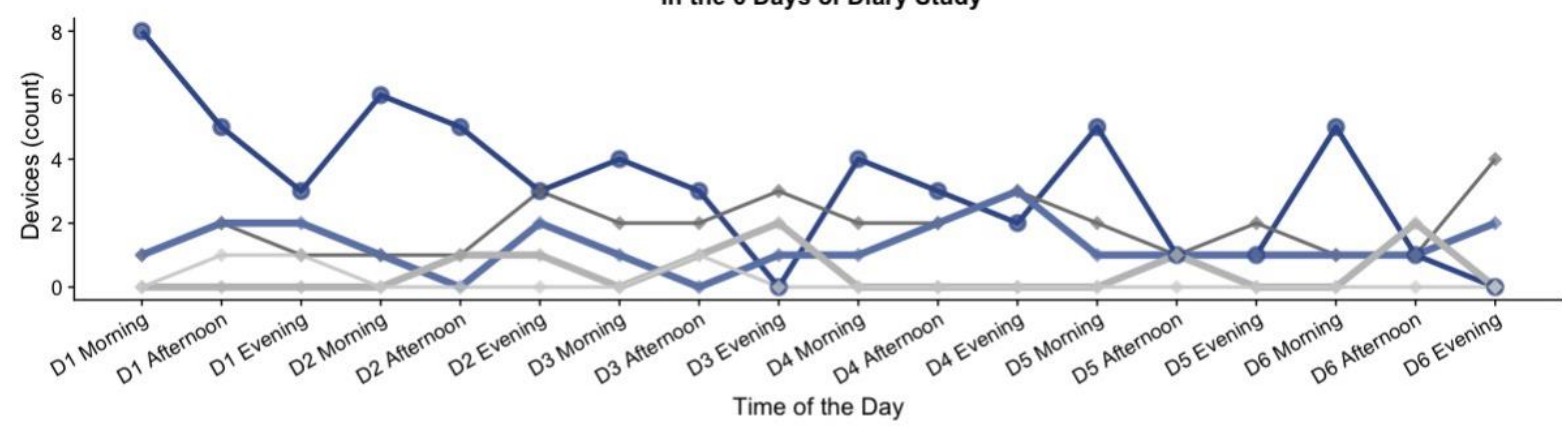

Device $\odot$ Radio $\rightarrow$ DVD. player $\approx$ Laptop.Computer.and.streaming.services $\approx$ Mobile.phone $\div$ sheet.music

(b)

Number of Participants performing Community Music Activities in the 6 Days of Diary Study

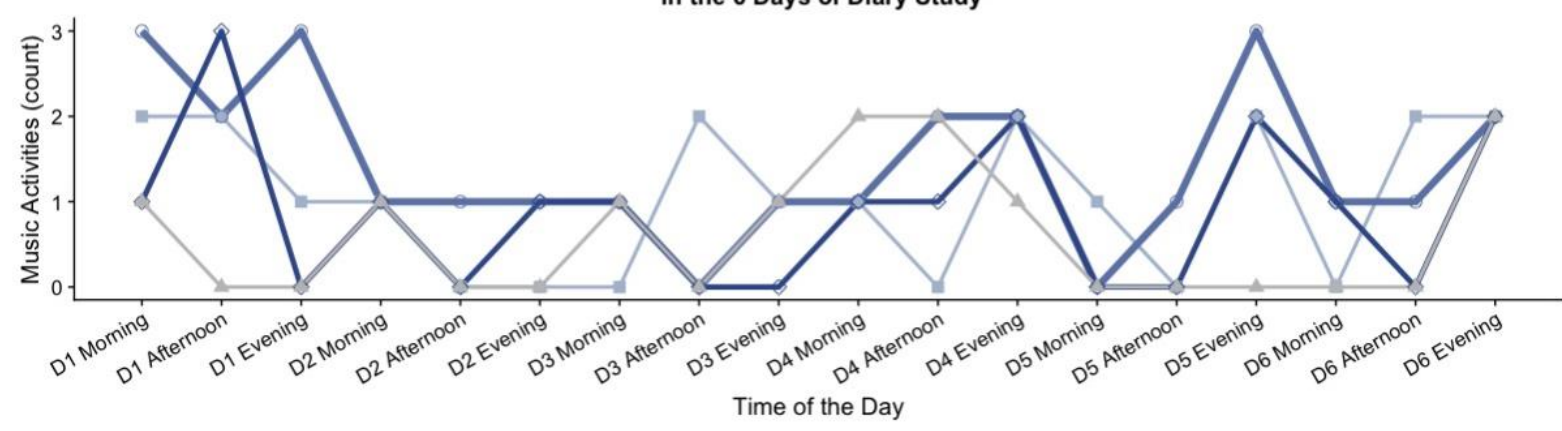

Activity $=$ Listening $\triangleq$ Singing.or. Rehearsal $\Leftrightarrow$ Performance $\triangleq$ Practicing.by.oneself

Figure 2. Number of participants (a) using music technologies and (b) performing community music activities in the 6 days of diary study

The audio recorded interviews were all transcribed. Data analysis adopted a grounded theory approach using the constant comparison method (Corbin \& Strauss, 2008). NVivo 11 was used for qualitative analysis. Much of the analysis of interview transcripts was conducted simultaneously with data collection. Transcribed interviews were analysed with a focus on how emergent practices around technology developed, how and when technologies were used, and why participants used technologies in their particular ways. At first, two researchers (including the first author) did the open coding of six transcripts independently, during which memos were written. Then the two researchers iteratively discussed the emergent codes and categories. Examples of initial codes are "being part of a community", "music sharing", and "workshops", which are related to the higher-level category of "participation in community music". Then the 
first author proceeded with coding the remaining interview and diary data, and related new data back to the emergent codes. The primary set of emergent codes were used to iteratively code all the interviews, diary data, and observation field notes again, and newly emergent codes were added into the primary set. After that, we compared codes with regard to different demographic characteristics (e.g., education, age, employment status, music expertise, and technical skills), and used axial coding and selective coding to form themes. Then we returned to all the previously analysed data and investigated them again with the newly formed themes. Finally, emergent themes in terms of their properties, and the structural relationships among themes were generated from data. The diary data and field notes from the participatory observation were further compared against and confirmed by the emergent themes from interviews. The emergent themes included: music learning by sharing, music revisiting, exercising control, role transitions and forward-facing identity. The recurring theme of forward-facing identity was further discussed with specific reference to the situated use of technology.

\section{Results}

To answer the first research question, we identify patterns of the situated use of technology around meaningful participation. Then we move to the second research question by unpacking the ways in which participation is associated with identity development and proceed to discuss its implications for active ageing.

\section{The Situated Use of Technology for Meaningful Participation}

\section{Sharing as a learning practice}

In the context of community music, sharing recorded music files to the choir was an essential tactic for choir instructors to facilitate music teaching/learning, rehearsal, and 
performance. In accordance with the findings of our prior ethnographic inspired research (Mao et al., 2016), 9 out of 10 interviewed participants of community music were aware of the music recordings, links of music, MP3 files, and sheet music that were distributed from the choir leaders/instructors and used them at different levels. The practice of sharing was dependent on an assembly of music possessions and technologies and a network of "sharers" and "recipients".

Usually, music instructors played a role as distributors; participants acted as recipients and content producers. Sharing practices initiated by music instructors often occurred in 'off-rehearsal' situations - not during rehearsals or performance but after or before - such that participants could learn the pieces with shared recordings by themselves or in small groups or other casual occasions (e.g., party, social gathering). Music instructors recorded music and shared the recordings with the choir via e-mail or burned CDs. The overwhelming use of e-mail for sharing corroborates earlier literature that social sharing practices through YouTube among older people were mainly relying on e-mails. As a choir instructor put it, sometimes "with the choirs I [the choir instructor] bring my recorder, and I record some songs, and later I can [burn] it to CDs for people" (P11). Aside from e-mails and CDs, posting on websites owned or managed by choir instructors was another way of sharing. Choir instructors reported uploading music to their websites or cloud storage/streaming platforms (e.g., Dropbox, SoundCloud). Some music instructors ran e-mail discussion groups with music teachers to share information, music, and experiences of teaching. Moreover, choral music websites run by third-party institutions were also popular among our participants. Three of our participants mentioned their use of ChoraLine - a choral music resource hub that enables community musicians to share and receive information and get support from choir leaders (see Figure 3). 
Occasionally group participants who had skills or technical facilities for recording music took up the role of recording music, and choir instructors helped with the distribution:

"Somebody [one of the choir members] records the session every week, and I [the choir instructor] put it onto Dropbox..." (P11)

"We got a choir member who used to work for the BBC (actually) as a recording technician, and he is recording all the music on our concerts when we first began in twenty (something) years ago. So, we've got a huge collection... They are in CD form, and it is limited just to our usage.... We joined with other choirs, and they have a big mass choir. And [the choir leader] put those songs on Dropbox, so we can access them, and learn the songs. Because we don't actually learn them in classes, we do it by ourselves at home. And then we get together for a couple of weeks, or sessions, before our performance, [and] go through them." (P03)

How do participants perceive and use shared digital recordings? Not all participants thought the recordings were useful. Three participants who were members of formal music groups explicitly mentioned that they ignored those recordings because they were too simple or "sound weird". In particular, those who can play instruments (e.g., piano) found learning new vocal lines while playing the piano was more straightforward, compared to listening to shared recordings on the computers.

"I ignored them [recordings from websites such as ChoraLine]. Well, I just think there is a website that you can go to, and I just don't use it, because I found it so much easier sitting down at a piano, with the music in front of me, I can check what I want to check, and if it is a difficult bit, I could then immediately go to that bit and do it again. Sometimes I would play five times to make sure it moves into my head." (P09)

In contrast, shared music recordings were perceived as helpful among those who cannot play instruments or had problems seeing or reading sheet music. Participant 08 seldom downloaded music from ChoraLine but preferred buying burned CDs. He 
mentioned his casual music practicing with two other Basses in his choir to go through the pieces they were learning. Before getting the recordings ready for small group practice, he had to go through a few steps to transfer music between different devices:

"I was able to download his [the name of a choir instructor who had a website "Learn Choral Music2" with the similar functions as ChoraLine] MIDI files, and put them onto a CD by myself, and put it into my MacBook Air, you know, you can put things onto [the computer] as MP3 files, and I put that files on memory disks. Because one of my colleagues is blind, or pretty nearly about blind, and he can only use MP3 files." (P08)

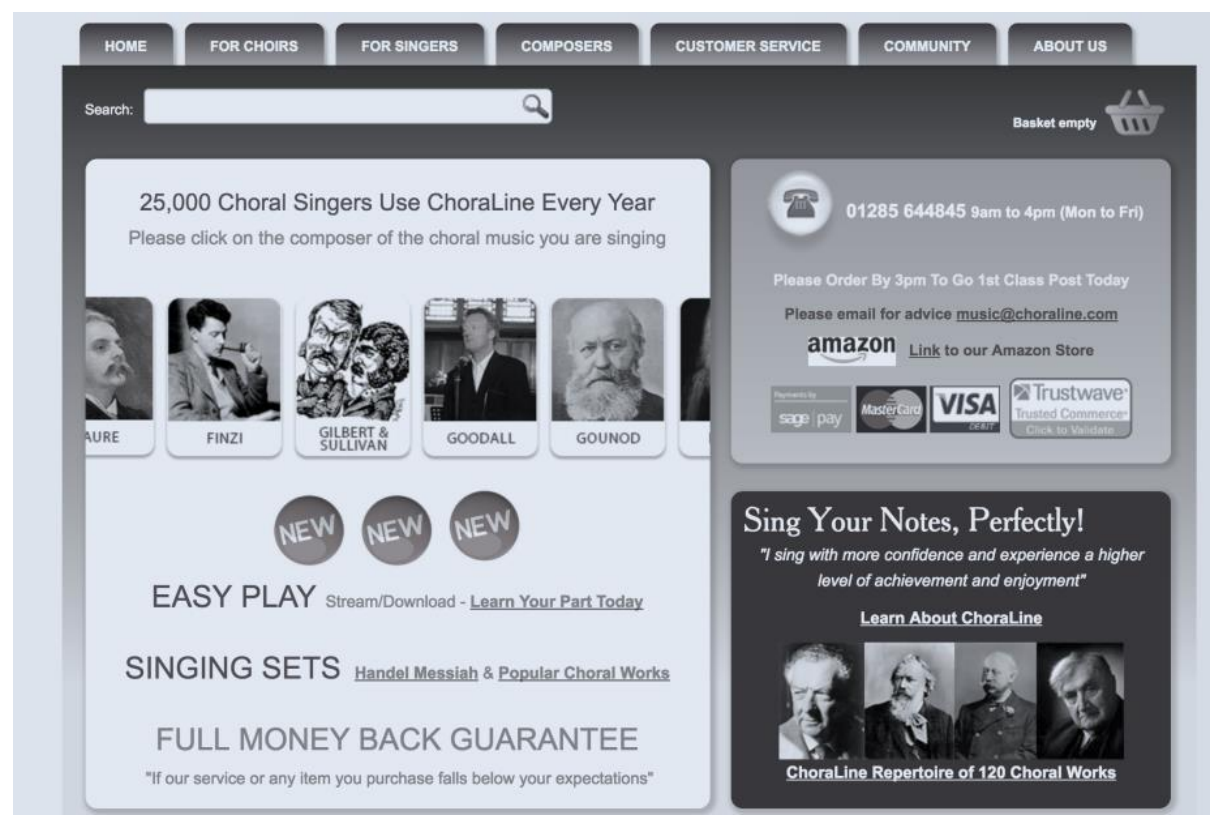

Figure 3. A screenshot of www.choraline.com

Over time some accumulated recordings became possessions with reminiscence functions. Shared recordings were not only perceived as useful for sustaining learning and helping with improvement in competence, but also brought enjoyment and shared 
memories. P02 kept a habit of saving most of the recordings of performances and rehearsals, as "it is part of our life":

"On Saturday we sit down and [listen to] MP3 [of music that we have learnt] by now. And then we practice, and then I saved it [the recorded rehearsals] on the laptop.... I actually save my music file section on my laptop, which I am proud of. They are all there, you just need to [save them] because when [we] did a concert in December in [name of a cathedral] and we were singing songs that we learnt from another one [choir] in summer [...] Yes, I keep them. I actually save them.” (P02)

Sharing music for reminiscence among participants occurred face-to-face by talking about the experiences, browsing the recordings together, and revisiting them in groups. For example, participant 07 mentioned her music sharing with her daughter, and participant 03 expressed the enjoyment of learning music together by sharing the recordings with other choir participants:

"She [the daughter of P07] has to look up my files and what we do and listen to [recordings from the choir]. She doesn't always agree with the arrangements." (P07)

"We were learning songs all the time, and some people recorded them right to the end when we went through what we've learnt. On the last night, we went through what songs we have learnt in the two weeks. It was really lovely, really nice." (P03)

The distinction between formal and informal community music groups in part accounted for the differences in perceiving and using shared music recordings. In particular, formal music group members or those with a higher level of musical expertise tended to perceive shared music recordings as less useful. However, we lose the subtleties of the whole picture if we stop here. The "complex assemblies" of music and various technologies and confidence associated tell another part of the story. As we have noted in P08's case, music sharing comprises an effective and efficient sequence 
of multiple actions such as downloading, searching, e-mailing, playing, copying and transferring. Technological tools played a coordinative role: personal computers (and other devices) were used for storing and retrieving digital music, getting access to repositories for resources, as media through which music are reproduced and transferred, and also as sound amplifiers (Leong \& Wright, 2013) for individual or group music-making. This also contextualised the data drawn from the diary logs that performance and rehearsal were positively correlated with the use of computers and streaming services. The situated use of technology was a consequence of the fact that technologies fit into an "existing network of already familiar equipment” (Shove, 2007, p. 78).

Meanwhile, digital music files and technological devices should have the capacity for quick adaptation such that sharing can be reproduced and sustained. Occasions that require adaptation include technological innovations (e.g., cloud storage and streaming services are introduced to community music participants by their music instructors), accumulation of music competences, and the accretion of technological knowledge. Failing to link music-technology complexes to competence may impede the legitimisation of technology uptake and subsequently discourage people to share. For example, even participants who utilise shared recordings often, or who value shared recordings, mentioned that they faced challenges whenever they manipulated or played the digital files on their personal computers.

\footnotetext{
"You can't do that [playing a difficult bit many times] so much on ChoraLine, God knows, you will have to press the go and backwards button and then you wouldn't go back to what exactly you want to go to." (P09)

"I don't tend to [share music online or downloading music]. [I] don't have the confidence now. ... and I don't have to [do so] ..." (P02)
} 
In summary, sharing music recordings in support of meaningful participation was dependent on a complex assembly of music and technologies. Technologies played many different roles under the umbrella of coordination in support of music learning. The situated use of technology surrounding music sharing entailed a dynamic, codependent relation between sharing-related actions, technological tools, and competences. In particular, as individuals' competences accumulated, this had the potential to transform the way in which music was shared and prompt the acquisition and adoption of new technologies.

\section{Revisiting, learning and managing}

Another prevalent, technology-mediated practice was revisiting what participants already have. In some cases, participants revisited music that was shared with them by others (e.g., shared recordings from their music instructors), therefore making it hard to tear apart revisiting and sharing. In the interviews, we asked the participants to reflect on their digital and physical music collections, how they collected, used, and managed their music collections, and the reasons for using these. We found that revisiting practices were prompted by different occasions such as learning music in different variations, the intentions of organising, replacing and discarding old collections of music, acquiring new music, upgrading and reconfiguring existing technological devices. What the various occasions have in common is that participants have to deal with music possessions and a variety of technological devices by negotiating the interdependence among what they have, what they do, their competence and openness to learn to use these technologies and their forward-facing self-concepts.

One of the occasions, revisiting for the purpose of learning, was prevalent among all of our participants. Revisiting for learning entails proactively acquiring new 
music, in addition to receiving shared music, as discussed in the previous section. Diary data on "notable music moments" showed that all participants reported learning music in the performance repertoire at least once during the week of completing the diary book (see Figure 2-a). Among our interviewed participants, 7 of the 11 mentioned acquiring new music for learning purposes. Three participants (P06, P08, P09) explicitly reported that they bought music that they were about to sing or perform. They usually got a brief idea of what to buy from the performance repertoires of the group or recommendations from community music connections. Ways of acquiring new music included purchasing CDs and using streaming technologies (e.g., YouTube, Spotify, for those who had the readiness of using new technologies). A generic observation is that purchasing new music among our participants is often prompted by goals and expectations in relation to current meaningful participation.

For some, revisiting supports learning in a way that participants were able to grasp the subtleties of the music. Two participants (P04, P05) with a relatively higher level of music expertise reported this. As P05 put it:

\footnotetext{
"Sometimes I consciously want to retain a number of the recordings, [I'd] go [through] every variation, probably six recordings. And I do have a favourite, but I play the others from time to time. Because there are different interpretations, but as I said earlier, Spotify enables me to do that." (P05)
}

Participant 04 talked about similar experiences of learning from different versions of music on YouTube and developed her own strategies of differentiating highstandard recordings from the overwhelming search results. Indicators of standard included the performance venue, names of performing groups, as well as the age of performers (if available in the snapshot). Participant 04 only deemed performances in well-known venues and by trustworthy orchestras of a high standard: 
"Sometimes you can get a clue perhaps as the place that they are singing from: if this is somebody who is singing from Vienna or Paris, it is much more likely to be of a higher standard, because they've got so much competition. Whereas if it is somewhere in the middle of nowhere, it is more likely to be a local person who is really proud of what they are doing, but [the quality of the music is] perhaps not very good" (P04)

"All sort of [music on YouTube] has been done by very bright young kids who made enormous progress technically, but they haven't got any music in them at all. [These recordings] lack musical expression." (P04)

Alternatively, revisiting occurred when participants were facing the need to downsize, and deciding which music collections to retain/discard. Sometimes such situations were prompted by retirement, moving home, or technology innovation, e.g., upgrading music storage/playing technologies. Selecting and getting rid of music possessions was mentally difficult and sometimes painful because their music possessions are "anchored in the past" (Shove, 2007) and with strong emotional attachment:

“... Actually, some of the strong bits of musical memories connected with my [music] records. ... And I was very sad to have to get rid of them, because ... you know, everybody moved on to tapes, and then it all moved on to CDs and so on, and each time you think, 'well, I had it all, I had listened', because everything was very cumbersome, and took up so much space,..., so like everybody else I got rid of them, but actually I found they would have very strong memories" (P04)

As we have mentioned before, participant $05 \mathrm{kept}$ a number of variations of music collections. He had retired one month ago at the time of interview and was moving books and documents from his prior office to his home. Accordingly, he had to negotiate with his wife about making room for his stuff stored in his office: "we are reaching the point that we couldn't fit any more in the space [at home], [and] we have to start selecting”. One tactic of doing so was to downsize the music collection - 
transferring music on CDs to minidisks to save more space without losing the music. During downsizing, he was "forced to listen to everything that [he has] got ... because of comparing". In the meantime, he found streaming music technologies (i.e., Spotify) useful for retaining music while avoiding the long and tedious process of transferring music between devices. In this case, the potential of Spotify was accurately perceived a large online repository of music collections that would be sufficient to cover his own physical collections. Also, the affordance of music streaming services could potentially mitigate the mental burden of "relinquished" music collections, much as Lindley and Wallace (2015) suggest that technologies may be able to support the saving and presentation of the memory of "relinquished possessions".

Participant 05 reported another case in which he fixed the problem of connecting his old (but still good) sound system to his streaming devices. He reconfigured old and new technologies to his existing practices of music, such that the independent musical 'selves' of enjoying a massive music resource and also high-quality sound systems were effectively maintained.

\footnotetext{
"I've got Spotify there and then the Sonos, [but] I can't use it now. What it does is that it controls the speakers in my house through which I can stream Spotify or radio to the speaker. It [the Sonos] has a unit, which allows me to stream [music from Spotify], and [recently] it is saying "I can't find the system". I think it [the Sonos] is a wonderful thing. In my living room, I have another thing, which is called the Gramofon: it is a little box plugged into my amplifier and that allows me to stream through my old 30-year-old sound system. I felt that the Sonos had a nice sound, but not really [as] the quality with the old system. Now someone told me about the little thing, which costs about 40 pounds. You just plug it into the back and then, you are using your own system with the quality of the old system, fantastic!” (P05)
}

The above examples of revisiting pointed to a recurring theme that new technologies (e.g., streaming services) are contingent on existing community music 
practices. Situational factors and future-facing identities prompted the practices of revisiting and related practices such as acquiring new music and learning to use new technologies. The ownership of new technological tools may engender new expectations, and further reconfigured existing practices, such as the adoption and use of new technologies in support of meaningful participation. In the case of P05, some of his music consumption transformed to digital formats while the rest was highly dependent on the conventional devices (e.g., the old sound system). He managed to keep having and doing (Shove, 2007) in provisional balance by actively adapting his routine practices to the expectations of benefiting from and the competence of using streaming technologies. The uptake of music streaming technologies was legitimated through an enduring connection between revisiting music collections, forward-facing identities, and the competence with such technologies.

\section{Identity Development in Meaningful Participation and Technology Use}

\section{Exercising Control3}

Exercising control and self-growth goals. The theme of exercising control first emerged in the course of the interview with P08 when he talked about how he transferred technical knowledge from a different domain in support of meaningful engagement in community music. He used a master's-level course and a three-month sabbatical in his 50s to learn to use technologies. These technical skills further proved beneficial in helping him find information, search for activities, learn music using

3 In this paper, we adopted Bandura's (1977) notion of control that perceived control can be treated as analogous to self-efficacy. The measurement of self-efficacy requires domainspecificity for accuracy (Bandura, 1997), therefore, in this section, we talk about selfefficacy and confidence inherent in ageing (Liddle et al., 2013). Control over the use of digital music technologies will be specified in later sections. 
online resources, stay connected with friends/family and music group members, and develop a sophisticated judgement of the authenticity of information on social media. He "now use[d] a computer quite a lot" and had "access to a lot of things that he has never ever thought [he] would have before". For him, the desire of improving his technical skills reflected his need for self-growth. His use of ICTs was perceived as a means of exercising control over his life at the age of 50 by continually learning new knowledge. His technical skills accumulated from the master's-level course were somehow "standardised", spread, and reproduced into active music participation.

In addition to technology-related self-growth goals, some participants achieved their self-growth goals in music through participation and reported an increase in the sense of control and accomplishment (for more details, see Mao et al., 2016). For example, P10 experienced growth in her personal music skills, and this surprisingly improved her self-efficacy with music. Participant 08 's technical skills helped them improve the effectiveness in achieving self-development goals and enjoying meaningful participation. New technologies extend the range of what participants are able to do, by redistributing the competences between them and their technological tools (Shove, 2007). In other words, new technologies were adopted not merely in a sense that they were eventually appropriated, but in the sense that self-efficacy and the conceptual appreciation of what these technologies can do were effectively grasped and reconfigured.

Exercising control and relational goals. The adoption of new technologies was also perceived as a means of exercising control when realising one's relational goals. Gaining facility with new technologies helped participants fully engage in every element of community music activity, in terms of having a common language with other group members, as well as feeling control over maintaining social relationships. For 
example, the motivation of one participant's adoption of YouTube was influenced by her social network of music:

"I was forced to learn how to use YouTube. Because the choir people keep saying,

"Oh there is a wonderful recording on YouTube, and listen to that", whereas before

I had never watched [videos on] YouTube." (P04)

Lack of control or lower self-efficacy may impact the realisation of relational goals. The process of accumulation occurred through participation and took time (Bukov et al., 2002). In many cases, self-efficacy in technology use contributed to a higher level of control; and technical skills and self-efficacy together sustained the enactment of the emergent music practices mediated by technology. In the interview, four participants mentioned that they were keen on seeing photos shared within groups, especially after group trips or performances. These photos were of value for shared reminiscence or self-presentation. For instance, participant 06 sometimes put those shared photos "on [her] website and [did] tell her friends where it is". Two participants (P03, P04) became interested in trying out cloud services with similar motivations but became frustrated when they were unable to save photos to their personal computers:

\footnotetext{
"Somebody has sent me something, in fact, it was from the choir, with pictures from Dropbox, and I set it up, and then I got it a real mess and I deleted it [Dropbox]. And I decided that I don't want to be in that [using Dropbox], and then somebody else send[t] some photos from Dropbox, and I thought, I would quite like to see them but [using Dropbox is not easy for me]. And then I am not on Facebook, either, I refused to go on that." (P04) "The first time I used [cloud storage] was [for] the photographs, shared photographs. There are practically nicer ones from someone else taken... unfortunately, my computer wasn't [working properly], so I haven't been accessing [those photos]." (P03)
} 
We are not suggesting that those who failed to use or do not use technologies were unable to exercise control when actualising their self-growth or relational goals. Exercising control was dependent on technological tools only when these technologies had been defined and configured by existing community music practices and an existing network of music possessions. Alternatively, participants sought workarounds that worked best with their existing practices (e.g., P08 preferred buying CDs from ChoraLine to downloading recordings from the website). This finding echoes the notion of "proactive coping", that people are active in seeking alternative means to desired outcomes of active ageing rather than passively accepting (Ouwehand et al., 2007; Stenner et al., 2011).

\section{Supporting role transitions in a time of change}

In our data, two participants related their technology use to their life experiences in transition. Participant 09 lost her husband four years ago. She previously relied on her husband for information and technical help. She "started using technologies a lot more" since then, and she felt the need to "find it out herself' for almost everything. In this case, technology use in general symbolised a transition to a more independent role. This also indicates that the use of technologies mediates daily practices in a time of change.

Music streaming technologies coordinated the ways in which our participants managed and reflected on their new spatial and temporal arrangements after retirement. Participant 05 retired one month ago and was experiencing the challenge of renegotiating and re-arranging the limited spaces at home. As we have mentioned in the section revisiting, learning and managing, he found a workaround to transfer CDs into minidisks and MP3s, so as to save space at home. He decided to do so right after 
retirement. However, during the course of our interview, he mentioned that he began questioning the value of doing so:

"I found it [transferring music] was too time-consuming. I am not a patient person. It is because of patience that I was to sit down, to give out the time and play. I just wanted to work." (P05)

His notion of "time-consuming" implies that the practice of transferring music with technologies may not configure itself into his existing, valued life routines. He further justified this with his perception of the affordance of streaming technologies:

\footnotetext{
"Why should I, where I can do stream music. So why spending hours, creating CDs or computer files when I could have what I want, I mean, the wonderful thing about Spotify is that we all know every recording is there and there are a lot." (P05)
}

A few retired participants (e.g., P10, P08) retrospectively mentioned their worries of being isolated and being incompetent following retirement. In such cases, retirement was a catalyst for future self-development, and motivated participants to seek opportunities for social participation. Technology, although not mentioned explicitly, manifested itself in different ways: it coordinated active participation, and supported improved self-efficacy as the skills of using technology accumulated. In other words, technology use supported role transition in a time of change by assisting participants actualise their desired identities, which were always connected to notions such as "stay busy", "being active", "not old", etc. Such identities have implications for active ageing by enabling self-actualisation and empowering people with resilience in a time of change (e.g., Ekerdt, 1986; Rozanova, 2010; Lazar \& Nguyen, 2017). 
Community music was not just where group music-making is carried out. Rather, it functioned as a "social space" (Taylor et al., 2016, p. 1418), which is defined as "hubs of community, where people come together to work together, learn from each other, or simply socialise". All our participants reported that they "incidentally" made friends from music groups. Unless established earlier elsewhere, the friendship built from community music was highly contextual. Likewise, social circles drawn from different activities or hobbyist groups were perceived as "isolated" (Nippert-Eng, 1996). All our participants were comfortable with this contextual, hobbyist-based, lightweight camaraderie, and accepted the natural shift in the social network from work colleague circles to "isolated" and "contextual" relations after retirement:

\footnotetext{
"That's [making friends while singing] gonna be incidental. But when you retired, you are no longer in that central position, nor do I necessarily want to be, but you do make friends. But things are getting slightly contextual ...” (P08) "I suddenly realised this the other day when I ... you have people for lunch, things, but they are totally different individuals. And every route seems to be isolated, dancing, choir, I see them on street... but no other contacts." (P07) "It tended to be friends I see at choir, and we are friendly. We go to pubs afterwards, that sort of things. But there are very few of them that people I see outside of that context. Some of my old friends joined the choir, [and] we do things in other contexts." (P10)
}

Also, our participants attempted to manage the boundaries in offline contexts. For example, participant 10 found it strange to share her experience of choral singing with her other friends: "I seldom try to sell my tickets [to my friends and family not involved in community music] - it's very weird." Participant 08 recently bought tickets for his extended family members to attend one of his concerts, but he doubted that they 
would be willing to "come again with their own expenses" and the music he performed was "not in their normal area of musical experience".

Re-distribution of competence in social spaces. As mentioned in the section exercising control, requisite competences of meaningful participation were distributed between music group participants and technological tools. Here we extend the observation further and argue that competences are also re-distributed between different people, resulting in the formulation of different roles at the group level and perceived social support at the individual level. For some, the competence with technologies was allocated to another "technological person" in their social network. This person could be a family member, a friend, or a group member.

\begin{abstract}
"She [a music group friend] loves anything technological. I just give her an idea [and] she is aware. She is much more confident with her ... computer, iPhone, or whatever. And, um, she is not a good teacher because she goes too fast. Then I can't remember what she says. ... I have to be the sort of person write things down to ... maybe [I feel] yes, that [is] for what to do first, then that, then that... right click, left click, whatever on the computer. Literally I put everything down [in a notebook]. I've been [interested in] learning something new." (P04) "I have somebody in my choir. He has a free space - he doesn't pay to come. As an exchange of that he is the Sibeliusaman. So, if I've got something, I send it to him. He can get it mixed, he could get it not for money, but as a skill. And he likes to do that." (P11)
\end{abstract}

In the case of P04, competences were distributed between the participant herself, her "technological" friends, and her written notes as supplementary memory aids. For P11, she was happy to offer free entry for the group member who was a great help to

4 Sibelius is a commercial scorewriter software developed by Sibelius Software. It is used by music practitioners. The main functions of Sibelius include editing/printing scores, playing music back, and producing legible scores for editing, printing and publishing. 
her in editing music files with a professional music editing tool. The roles within her choir were re-distributed. The reciprocal relationship among group members and friends contributes to perceived social support. As such, participants constructed a sense of others through receiving and giving help within their groups. The sense of others further contributed to an increased level of mutual intimacy and reinforced the perception of group norms. Past research shows that perceived social support is an important source of positive emotion in one's later life, as social cohesion formed through groups provides "buffer zones" between psychological stressors and well-being (Cramm et al., 2013). Also, active ageing literature suggests that the reciprocal relationship in "social spaces" impacts participants' health and well-being via psychological pathways of selfefficacy. In the case of our data, technology-mediated practices in the "social spaces" of community music have positive implications for active ageing.

\section{Tensions in identity management online}

Our interview data revealed tensions in relation to identity work when participants failed to manage their multiple self-presentations online. In particular, the emergent practice of sharing music with streaming technologies (i.e., YouTube) brought the challenge of "context collapse" (Marwick \& Boyd, 2011). Participant 07 mentioned the tension she experienced when having discovered a video of her being posted on YouTube by one of her choir friends. Her first reaction was surprise: "I was not told that I was to be put up on YouTube, so it was a bit naughty." Later, she found the humour in it and told a few friends to look it up. However, she had concerns over the accessibility of YouTube among friends of her age: “I don't have people who had ever looked at it, and [my friends] used [YouTube] rarely." Later, this situation triggered new concerns about her self-presentation online and her desire to control her own 
privacy:

"I don't know if YouTube takes things down after certain time or something. I would not have chosen [...] if I was going to pick a video or even audio of mine, singing to a public domain, this is not the situation I would have chosen. I've got much better recordings of that" (P07)

The participant explained that her concern came from the blurring boundaries between her music circles and work colleague circles: "if you Googled me, maybe [you] wanted to know about my professional activity or something, but what you've got was me in evening dress singing a lovely but old-fashioned pop song." Similarly, P05 also expressed his unwillingness to share the music that he listened on Facebook, because he did not want to blur boundaries between his music circles and the circles of colleagues and students.

In the case of P07, tension arose when participants intended to share their experiences and feelings of community music participation but had little knowledge of boundary management with social media or music streaming services. As mentioned in the section on the situated use of technology, browsing music recordings of rehearsals/performances and sharing photographs of performances and group trips faceto-face were prevalent and enjoyable activities. Here YouTube had proved to be a double-edged sword: it saved the effort for sharing to some extent, but it also brought new problems and concerns to our older participants with little knowledge of the tactics of social network sites (e.g., using nicknames, obscuring real identities online, controlling privacy settings). This finding resonates with other online actions such as "un-tagging" on social network sites among young people (Besmer \& Richter Lipford, 2010; Lang \& Barton, 2015). This may result in anxieties in relation to self-presentation - a phenomenon that is common offline (Baumeister et al., 1989) and has become 
apparent in online communication contexts among younger generations (e.g., Farnham \& Churchill, 2011; Thomas, Briggs, Hart, \& Kerrigan, 2017). To this end, we provide a concrete case of the experiences of "contextual collapse" of community music in old age.

\section{Discussion}

use have answered two research questions regarding situated technology use for community music participation and its association with identity development. In the preceding sections, we first drew from findings on RQ1 to unpack the complex role of technologies in sustaining community music participation. We then sought to illuminate aspects of meaningful participation and active ageing that could be supported more generally from findings on the association between identity development and community music practices (RQ2). Clearly, these practices identified above cannot be generalised to all music practices, and technologies that are contingent on these practices need to be discussed in specific contexts. In the following sections we write about implications for technology adoption, followed by reflections on ageing through practice-oriented research.

\section{The Role of Technologies in Sustaining Community Music Practices}

The participants' accounts with respect to technology-mediated practices illustrate an unsurprising fact that participating in community music digitally means carrying out practices like sharing, revisiting, recording, managing, and transferring music with the help of "complex assemblies" (Shove, 2007) of technological tools and music possessions. Drawing from social practice theory (e.g., Shove, 2007), the doing of community music practices (i.e., sharing and revisiting) was sometimes contingent on having and learning to use digital technologies. Technological devices function as a 
new, constitutive element of conventional music practices. Then we ask, how do such technology-sustained practices emerge and develop? How are these practices dependent upon technologies with respect to having and doing?

\section{The development of emergent technology-mediated practices}

Our participants' use of existing, conventional technologies (e.g., MIDI files, computer, MP3, CD players) and their music possessions had already reached a provisional balance between having and doing. They chose to say with their familiar technologies and kept them congruent with the routine music practices. However, on some occasions, life changes and events may challenge the established equilibrium and lead to uneasiness (e.g., P05's downsizing case, P04's uptake of YouTube due to social pressure from peers). As such, the provisional balance between practices and technologies goes beyond merely acquiring new technologies and getting rid of old ones, but also entails learning to use new technologies and having new technologies as possessions. Having is contingent on doing, such that the technology-competence linkage and technology-meaning linkage are reproduced and transformed potentially and might shape the future development of practices (Shove et al., 2012). We therefore discuss the development of those linkages in more detail through the theoretical lens of social practices.

First, technologies were adopted when they were incorporated into an existing framework of expectations and competences established by music sharing or revisiting practices. However different the individual trajectories are, sharing and revisiting music digitally become increasingly regular as more community music participants do it. In other words, technology legitimates itself as an updated element of community music practice when the technology-competence linkage is "reproduced and enacted" (Shove, 
2007, p. 88). Driving forces of the development of this linkage may come from practices or technologies, such as the availability of technological innovations, the accumulated technical and musical competences, and new motivations that emerge through participation (e.g., self-growth and relational goals). Even though most participants were aware of streaming and cloud technologies, those who eventually took up these technologies were aware of the prospective benefits and had mastered the necessary forms of competence, or at least, were willing to spend time learning such skills. Our findings resonates with Sayago et al.'s (2012), that email is among the most popular channel for sharing music, and participants developed their own strategies to share and make sense of shared music. For example, the URL of a piece of music on YouTube was seen by some participants as analogous to digital music files that they received as email attachments. For some, music resources on YouTube and Spotify were a substitution of their music collections. A lack of competence or interest in developing these competences may leave people with an "observer" attitude or the tendency of avoiding the feeling of incompetence (e.g., P03 and P04 gave up using Dropbox due to the lack of competence).

Second, digital technologies play a role in coordinating practices, through which self-growth goals (e.g., to learn new knowledge in later life) were achieved and social connections were maintained. Mastering technology was meaningful to some participants, as it aligned with their self-growth goals and forward-facing identities in response to life changes or the foreseeable future (e.g., P08's technical skills acquired through the master's course enabled him to be a quick learner and better musician). Also, meaningfulness can be constructed from a sense of belonging to groups. For some, this means that they were "forced" to use YouTube to stay tuned with conversations. Social psychology literature elaborates that the sense of belonging 
impacts the psychological field (e.g., Hopkins et al., 2016) of oneself and shapes future meaningful practices. Following this strand of thought, Creech, Hallam, et al. (2014) suggest that future-oriented and collective identities are vital for active ageing. Collectively with our data, situated technology use is meaningful to our participants, because these technologies are implicated in existing and future practices of community music. These findings extend the adoption path to new technologies, taking notions of competences, social connectedness, self-development, future-facing identities, and collective identity as core principles and elements.

\section{Incorporating technological competence as part of the community music practice}

Comparing cases of adopting and not adopting technologies in our data, we identified two reasons: not being worthy of time investment, and the lack of control over technologies. Holistically, both reasons point to the fact that technology use failed to be configured by existing practices from which meaningful participation was actualised. These findings further suggest that ambiguous affordances of these technologies may limit the perceived value and motivation of adopting these technologies. For example, P10 and P07 reported that they underwent an almost unconscious process when downloading music from websites or uploading music. Lack of control may hinder the adoption of technology and constrain the ways in which such technologies sustain community music practices (e.g., the difficulties of downloading shared photos from other members).

Here we adopt Kirk and Sellen's (2010) findings on the types of family archiving to further elaborate the tension due to lack of control and ambiguous affordances. Photos shared by other group members on the cloud entail reminiscence and storytelling functions and are termed as artefacts on "display" according to Kirk and 
Sellen's categorisation. In contrast, in the case of P10, cloud-based systems' affordance of displaying photos was not well grasped, and such technologies were actually "used" for "deep storage" - a method of storing artefacts out of mind and out of sight (Kirk \& Sellen, 2010). This tension implies that a digital system being introduced to older adults may provide easier and understandable ways of demonstrating its potential exploitation (i.e., in support of reminiscence and storytelling function via ways such as capturing information in relation to events, people, time, and place) and sustaining people's existing, familiar and routine practices (in this case of sharing and revisiting music in face-to-face occasions). This argument is backed by existing HCI research. For example, Gutierrez and Ochoa (2016) suggest highlighting the benefits of technology in family meetings, so as to satisfy older people's communication needs and enhance their willingness to adopt technology. In sum, we evidence how the absence of meaningfulness and competence of using technologies in practices might challenge people's technology adoption and will likely influence their experiences of participation.

\section{Leveraging Social Participation through the Practice Lens}

First, our findings point to the value of activities that demonstrate the skills and progress that participants have made through participation. Given that meaningful participation is cumulative, our results imply that technology preferences are associated with participants' prior technological experiences, the openness towards taking up new technologies through doing (i.e., sharing and revisiting practices), as well as their level of commitment to the community. As competences accumulate and develop, updated forms of practices may emerge, such as using music streaming services to learn music and replace one's existing music collections. Being aware of the accumulated 
competences may have positive consequences for participants' self-efficacy and confidence in realising their relational or self-growth goals. Therefore, we recommend that practitioners should look into supporting the visibility of progress and skills in community music (perhaps with technology as well). This implication resonates with some studies in HCI (e.g., Lindley \& Wallace, 2015; Massimi, Bender, Witteman, \& Ahmed, 2014; Taylor et al., 2017), which argue that demonstrating one's expertise and supporting knowledge sharing in social participation are especially important for healthy and active ageing.

There are a variety of ways of demonstrating skills and progress in community music practices. Practitioners should first identify activities or moments that concern skills and progress, such as the completion of a concert, learning a song, downloading a piece of music shared by others to one's laptop or MP3 player, or confidently getting sufficient information for one's future learning aspirations. As for informal groups that value socialisation more than learning, highlighting milestones such as the number of concerts that one has completed, the number of audiences that they have reached, and how many cities or venues that they have been to may help to build confidence among participants. Alternatively, music practitioners might highlight one's unique skills to establish a sense of reciprocity. Recognising roles (informal or formal) in groups, such as a technical person, a CD producer, a social media person, or even a painter for music5, could be beneficial in maintaining social relationships and sustaining community music practices.

5 See an example here: http://www.lucycavendishsingers.org.uk/gallery/paintings-lesleyfotherby 
A second way of leveraging social participation is by enabling competence sharing and technical support from different social circles. We noted that technical support from family members, although often occurring (e.g., Farnham \& Churchill, 2011; Wang et al., 2018), may not be available nor always be effective. Our findings confirm Wang et al.'s (2018) that technology is often introduced by older people's family members (e.g., partners, adult children, grandchildren). However, for some, they were reluctant to ask for help from their family because they did not think their family had sufficient time or patience. Gutierrez and Ochoa (2016) even note that the approach used by adult children to take care of their parents with respect to technology uptake may result in a "vicious circle": with tensions and stress engendered on both sides. As such, our participants tended to seek help from peers in their community groups.

In light of this, our findings suggest that developing new technical roles in groups (e.g., specialists with technical skills in Carroll \& Rosson, 2013) and enabling the reciprocal, informal technical help from peers (e.g., Müller, Hornung, Hamm, \& Wulf, 2015) may ameliorate the tensions of older adults' learning to use technologies from their family. For example, community music practitioners may consider setting up inter-generational networks for sharing digital skills in their groups (if there are younger participants who are more technology-savvy). Also, practitioners at U3A might reframe existing technology learning classes and other interests-based programmes (e.g., making the computer learning classes at U3As playful and situating some of the technical courses in local events and activities), so as to provide a productive and meaningful technology learning experience and support “skill-swapping” (Lindley \& Wallace, 2015). However, the informal technical help within community groups might not always be available, in which case practitioners might consider projects that pairing the older and the younger volunteers (e.g., Carroll, Convertino, Farooq, \& Rosson, 2012) or 
popup sessions6 in public places "hooking" people up and showing them the value and meaningfulness of technologies in solving their real-life problems.

\section{Considerations for Adoption}

In this section, we address considerations for technology adoption among older people more broadly. In previous sections, we discussed the reasons of not adopting new technologies from the practice perspective that technologies (having) fail to sustain community music practices (doing). Here we speculate how these practices could be utilised to enhance technology adoption to support community music and active ageing. These speculative considerations are not requirements generated for the development of systems, nor the so-called "implications for design" that Dourish referred to as "genre conventions" (Dourish, 2006; as cited in Lindley, Coulton, \& Sturdee, 2017). In particular, we consider ways of incorporating technologies to leverage social participation and, in the meantime, how competences and meanings could be incorporated into existing practices to support the adoption of technologies and sustain those practices.

Supporting new participants' experiences. Our recommendations of leveraging social participation are concerned with linking the family and friend circles with community music practices, so as to make those who are new to community music feel safe and confident, and to motivate them to go on with participation. Paper-based flyers on physical poster boards, digital flyers distributed via e-mails and websites are unlikely to reach the diverse audiences from family and friend circles. Digital technologies might be used to record, curate, and share such information, experiences,

6 The Down Memory Lane project by Age UK (2014) provides nice examples for such popup and taster sessions. 
and memories of community music participation and spread the enthusiasm of community music. For example, our observation shows that older people do not rely on social media for discovering information and events. However, social media could be a supplement to existing activity promotion channels (e.g., websites, email lists, and flyers) in terms of the groups' collective identities and might be utilised to attract older people's younger family and people who have little access to the existing information distribution channels of community music. Moreover, photos, streamed video clips of performances and rehearsals (some websites already have such information), and even rich media contents from a first-person point-of-view recorded by a head-mounted webcam (Light et al., 2017) might give a sense of participation and a vivid knowledge of the routine practices. This could be particularly helpful for those actively seeking engagement and new to such activities.

Support the sharing of experiences and memories. In addition to attracting younger family/friend circles to participate, the recorded and shared digital content, coupled with shared music repertoire, could provide a community repository (e.g., performance playlists, a memory of programmes and flyers). Such a repository can be curated by older adults' family or community practitioners to represent the memories and experiences of one's social participation in later life. Following Churchill, Nelson, Denoue, Huysman, wenger, \& Wulf (2003), technological tools in support of the collection, curation, and storage of such contents might provide valuable memories after the shared contents expire. The rich and vivid digital content could be used as "tickets to talk" (Sacks, 1992) or anchor points when older people spend time together with others. The digital character of such contents makes it more likely for the "young-old" who have been familiar with technologies and have had some digital traces with regard to their past experiences (e.g., participation in community music). On the other hand, 
with such a community repository, music group members (e.g., those who are keen on collecting paper programmes of concerts, mentioned by P10; those who are keen on initiating informal musical and social activities like P05) could contribute content, revisit these playlists, sing along to the songs, and reflect on the progress that they have made.

\section{Conceptualisation of Ageing through Practice-Oriented Research}

Following the active-ageing discourse, our findings suggest that ageing and the consequences of it are relevant in thinking about how technology sustains community music practices and why certain technological tools might be needed (Light et al., 2017). What emerged from our data is that the consequences of ageing, as well as the consequences of retirement, are associated with the ways in which meanings and competences of practices are enacted and configured. The findings with regard to the impact of health-related physical conditions on one's level of commitment to community music are age-specific. Though technological competences and prior experiences in some cases are inevitably different between those who are still in employment and those who retired 10 years previously, age itself does not emerge as an obstacle to technology use here (Molapo, Densmore, \& DeRenzi, 2017). The two most prominent reasons for non-use (i.e., lack of control over technology use, not being worth the time) in our data may apply to other age groups as well (e.g., Coyle, Moore, Kristensson, Fletcher, \& Blackwell, 2012; Kelly, Gooch, Patil, \& Watts, 2017). This implies that ageing is more like a circumstantial factor in contextualising changes in one's 50's and 60's (Light et al., 2017), and the changes may result in different levels of skills, confidence, motivation and identities. It is plausible that future older cohorts (e.g., the "younger old") have different landscapes of technology use from what have 
been documented in existing research, because they may be more familiar with (e.g., Friemel, 2016) or still be challenged by the ever-changing technological innovation.

These analytical observations provide a partial view and a practical way for HCI researchers to challenge the "deficit" model of ageing and the "prosthetic" model of technology. Thus far our findings, rooted in situated action and social practice theory, prompt us to focus on the dynamic relationships between having, doing, and learning (to use new technologies), and what it requires for doing. How we approach ageing and technology use resonates with the practice-oriented paradigm in Kuutti and Bannon's work (2014). The central issue is to develop the capacity to transform practices through technology. This body of work (e.g., S. Lindley, 2015; Kaptelinin \& Bannon, 2012; Wulf et al., 2015) highlights the importance of understanding the role of technological artefacts in the emergence and transformation of practices, and the possibilities in influencing the artefacts. We have noted that digital music technologies shaped community music practices by coordinating the complex assemblies of computer artefacts, music possessions, meanings, and competences, through which the development of practices was sustained.

Notably, one of the commonalities shared by our study and those existing, disparate practice-oriented studies is that the unit-of-analysis goes beyond individuals to practices. We draw two implications here. First, HCI research on ageing from the practice perspective may encourage us to decentralise old age in itself and focus on practices and the dynamic connections among things, meanings, competencies, and identities instead. What people have and what people do co-evolve with the introduction of new technologies over time and space (Shove, 2007). Therefore, people's needs are likely to change across time, space, and contexts. As such, HCI research is able to attend to the active ageing literature by providing understanding and technological 
interventions that support of older people's subjective, situated theorising of what it means to be "active". Second, the change of the unit-of-analysis decentralises technology per se, and implies a goal of making technological interventions useful, pleasing, and being "a good fit" to people's everyday lives. This partly echoes the notion of "intrinsic technology-enhanced activity space" (Kaptelinin \& Bannon, 2012), according to which technological interventions have a direct impact on people's practices. Also, intrinsic practice transformation is based on situated solutions that are appropriate for the concrete tasks. In other words, treating practices as the unit-ofanalysis helps move beyond techno-solutionism by attending to how technologies add value and fit into people's daily practices.

\section{Limitation and Future Directions}

First, our research has been exploratory with regard to how and why late middle-aged and older participants of community music experience their participation and technology use. We have not implemented technology in the setting of community music, nor have we conducted direct observation on their use of information technologies. However, following Suchman's situated action approach, it is essential to first explore how technology use is situated and grounded in people's everyday life and practices before actually introducing new technologies or changing existing technological settings. Instead of merely discussing ICTs in general, our findings provide initial observations with regard to a specific type - digital music technologies. Prior research with the ageing population highlights the importance of investigating the experiences and actual use of particular applications/technologies (e.g., Friemel, 2016; Yuan, Kropczynski, Wirth, Rosson, \& Carroll, 2017). Future research should put more emphasis on technological design and intervention in support of active, social 
participation with a consideration of older adults' life-course experiences (Vines et al., 2015) and the specific settings of social participation.

Second, as with any social science study, limitations in generalisability result from our qualitative approach to the research questions. The data was collected from a specific population in our location, and the conclusions drawn from this sample cannot be generalised to the late middle-aged and older population as a whole (though a series of studies on active ageing and community music in different locations in the UK pointed to similar patterns, e.g., Hallam et al., 2012). Also, the use of technology among even older adults (the 80-year-olds and 90-year-olds) cannot be extrapolated from this present research. Nevertheless, our approach and analysis illuminate the subtleties of active music participation, and the relationship between technology and community music practices (Dourish, 2006). It may be helpful in future studies of active participation (not necessarily being isolated within group singing) to apply similar analytical models of thinking (Dourish, 2006).

Third, the interview data was retrospective and drawn from past experiences of participants. As such, participants' accounts of their experiences of retirement, for some, were not able to support strong claims about the causality between retirement (or ageing) and actions (neither is the objective of our research). In this respect, the data provided here was a snapshot of the participants' experiences in this particular period of their lives. We acknowledge that lifestyle changes take longer (Batt-Rawden \& Tellnes, 2011); we are not suggesting a music-health causal relationship based on our data. Instead, our data depicts how later life self-identity and social identities are enacted from the continuous, successive performances of active music-making and technology uptake; how aspirations about health, self-development, and social relations are engendered and actualised; and how technology-mediated music practices develop and 
persist. Therefore, we would encourage readers to bear this limitation in mind when reading and synthesising the results.

\section{Conclusion}

In this study, we challenged both the "deficit" model of ageing and the "prosthetic" model of technology by focusing on "augmentation" of the active older adults (Blackwell, 2010), rather than correction of ageing. We contributed to HCI research by illuminating the particularity of technology use without the presumption of fixing problems caused by ageing. We investigated the situated use of technology in relation to meaningful participation in community music, and in particular looked at the coordinating role that technologies play in sustaining music sharing and revisiting practices. Moreover, by looking at how and why people use new technological tools in this context, the situated use of technologies and community music practices have implications for active ageing from three aspects: exercising control, supporting role transitions, and creating a social space in which forward-facing, collective identities are enacted. This study provides a nuanced picture of how community music practices are contingent on technologies, and implies ways in which community music practices can be sustained through the enactment of linkages between doing - engaging in community music practices, having, and learning to use technologies.

\section{Acknowledgement}

We gratefully thank Dr Siân Lindley, Dr Matthew Jones, and Dr Marta Cecchinato for their insightful feedback on earlier versions of this manuscript. We thank the Editor-inChief, the Editor, and the anonymous reviewers for the helpful comments. 


\section{Reference}

Adams, K. B., Leibbrandt, S., \& Moon, H. (2011). A critical review of the literature on social and leisure activity and wellbeing in later life. Ageing \& Society, 31(4), 683-712. https://doi.org/10.1017/S0144686X10001091

Alm, N., Dye, R., Gowans, G., Campbell, J., Astell, A., \& Ellis, M. (2003). Designing an Interface Usable by People with Dementia. Proceedings of the 2003 Conference on Universal Usability, 156-157. https://doi.org/10.1145/957205.957237

Bailey, B. A., \& Davidson, J. W. (2002). Adaptive Characteristics of Group Singing: Perceptions from Members of a Choir Forhomeless Men. Musicae Scientiae, 6(2), 221-256. https://doi.org/10.1177/102986490200600206

Bandura, A. (1977). Self-efficacy: Toward a unifying theory of behavioral change. Psychological Review, 84(2), 191.

Bandura, A. (1997). Self-efficacy: The exercise of control. Freeman.

Batt-Rawden, K., \& Tellnes, G. (2011). How music may promote healthy behaviour. Scandinavian Journal of Public Health, 39(2), 113-120. https://doi.org/10.1177/1403494810393555

Baumeister, R. F., Tice, D. M., \& Hutton, D. G. (1989). Self-presentational motivations and personality differences in self-esteem. Journal of Personality, 57(3), 547579.

Besmer, A., \& Richter Lipford, H. (2010). Moving Beyond Untagging: Photo Privacy in a Tagged World. Proceedings of the SIGCHI Conference on Human Factors in Computing Systems, 1563-1572. https://doi.org/10.1145/1753326.1753560

Blackwell, A. F. (2010). When Systemizers Meet Empathizers: Universalism and the Prosthetic Imagination. Interdisciplinary Science Reviews, 35(3-4), 387-403. https://doi.org/10.1179/030801810X12772143410485

Boudiny, K. (2013). 'Active ageing': From empty rhetoric to effective policy tool. Ageing \& Society, 33(6), 1077-1098. https://doi.org/10.1017/S0144686X1200030X

Bowling, A. (2008). Enhancing later life: How older people perceive active ageing? Aging \& Mental Health, 12(3), 293-301. https://doi.org/10.1080/13607860802120979

Bowling, A., \& Iliffe, S. (2006). Which model of successful ageing should be used? Baseline findings from a British longitudinal survey of ageing. Age and Ageing, 35(6), 607-614. https://doi.org/10.1093/ageing/afl100

Brewer, R., Morris, M. R., \& Piper, A. M. (2016). Why would anybody do this?: Understanding Older Adults' Motivations and Challenges in Crowd Work. Proceedings of the 2016 CHI Conference on Human Factors in Computing Systems, 2246-2257. http://dl.acm.org/citation.cfm?id=2858198

Brewer, R., \& Piper, A. M. (2016). 'Tell It Like It Really Is': A Case of Online Content Creation and Sharing Among Older Adult Bloggers. Proceedings of the 2016 CHI Conference on Human Factors in Computing Systems, 5529-5542. https://doi.org/10.1145/2858036.2858379 
Brown, B., Sellen, A. J., \& Geelhoed, E. (2001). Music Sharing as a Computer Supported Collaborative Application. In W. Prinz, M. Jarke, Y. Rogers, K. Schmidt, \& V. Wulf (Eds.), ECSCW 2001 (pp. 179-198). Springer Netherlands. http://link.springer.com/chapter/10.1007/0-306-48019-0_10

Buehler, E., Branham, S., Ali, A., Chang, J. J., Hofmann, M. K., Hurst, A., \& Kane, S. K. (2015). Sharing is Caring: Assistive Technology Designs on Thingiverse. Proceedings of the 33rd Annual ACM Conference on Human Factors in Computing Systems, 525-534. https://doi.org/10.1145/2702123.2702525

Bukov, A., Maas, I., \& Lampert, T. (2002). Social Participation in Very Old AgeCrossSectional and Longitudinal Findings From BASE. The Journals of Gerontology: Series B, 57(6), P510-P517. https://doi.org/10.1093/geronb/57.6.P510

Caldeira, C., Bietz, M., Vidauri, M., \& Chen, Y. (2017). Senior Care for Aging in Place: Balancing Assistance and Independence. Proceedings of the 2017 ACM Conference on Computer Supported Cooperative Work and Social Computing, 1605-1617. https://doi.org/10.1145/2998181.2998206

Carroll, J. M., Convertino, G., Farooq, U., \& Rosson, M. B. (2012). The firekeepers: Aging considered as a resource. Universal Access in the Information Society, 11(1), 7-15.

Carroll, J. M., \& Rosson, M. B. (2013). Wild at Home: The Neighborhood As a Living Laboratory for HCI. ACM Trans. Comput.-Hum. Interact., 20(3), 16:1-16:28. https://doi.org/10.1145/2491500.2491504

Carstensen, L. L., Isaacowitz, D. M., \& Charles, S. T. (1999). Taking time seriously: A theory of socioemotional selectivity. American Psychologist, 54(3), 165-181. https://doi.org/10.1037/0003-066X.54.3.165

Churchill, E. F., Nelson, L., \& Denoue, L. (2003). Multimedia Fliers: Information Sharing With Digital Community Bulletin Boards. In M. Huysman, E. Wenger, \& V. Wulf (Eds.), Communities and Technologies (pp. 97-117). Springer Netherlands.

Clarke, A., \& Warren, L. (2007). Hopes, fears and expectations about the future: What do older people's stories tell us about active ageing? Ageing \& Society, 27(4), 465-488.

Comber, R., Hoonhout, J., van Halteren, A., Moynihan, P., \& Olivier, P. (2013). Food Practices As Situated Action: Exploring and Designing for Everyday Food Practices with Households. Proceedings of the SIGCHI Conference on Human Factors in Computing Systems, 2457-2466. https://doi.org/10.1145/2470654.2481340

Corbin, J. M., \& Strauss, A. L. (2008). Basics of qualitative research: Techniques and procedures for developing grounded theory (3rd ed.). Sage Publications, Inc, SAGE Publications.

Coyle, D., Moore, J., Kristensson, P. O., Fletcher, P., \& Blackwell, A. (2012). I did that! Measuring users' experience of agency in their own actions. Proceedings of the SIGCHI Conference on Human Factors in Computing Systems, 20252034. https://doi.org/10.1145/2207676.2208350 
Cramm, J. M., van Dijck, H. M., \& Nieboer, A. P. (2013). The Importance of Neighborhood Social Cohesion and Social Capital for the Well Being of Older Adults in the Community. The Gerontologist, 53(1), 142-152. https://doi.org/10.1093/geront/gns052

Creech, A., Hallam, S., Varvarigou, M., Gaunt, H., McQueen, H., \& Pincas, A. (2014). The role of musical possible selves in supporting subjective well-being in later life. Music Education Research, 16(1), 32-49. https://doi.org/10.1080/14613808.2013.788143

Creech, A., Varvarigou, M., Hallam, S., McQueen, H., \& Gaunt, H. (2014). Scaffolding, organizational structure and interpersonal interaction in musical activities with older people. Psychology of Music, 42(3), 430-447. https://doi.org/10.1177/0305735613478313

Crescioni, A. W., \& Baumeister, R. F. (2013). The four needs for meaning, the value gap, and how (and whether) society can fill the void. In The experience of meaning in life (pp. 3-15). Springer.

Croom, A. M. (2015). Music practice and participation for psychological well-being: A review of how music influences positive emotion, engagement, relationships, meaning, and accomplishment. Musicae Scientiae, 19(1), 44-64. https://doi.org/10.1177/1029864914561709

Csikszentmihalyi, M. (2013). Flow: The psychology of happiness. Random House. de Muijnck, W. (2013). The meaning of lives and the meaning of things. Journal of Happiness Studies, 14(4), 1291-1307.

DeNora, T. (2000). Music in everyday life. Cambridge University Press. http://books.google.co.uk/books?hl=en\&lr=\&id=LXOhKHXUQeIC\&oi=fnd\&p $\mathrm{g}=\mathrm{PR} 8 \& \mathrm{dq}=$ Music + in+Everyday+Life\&ots=r8vGdGydP_\&sig=6OKdkJehRzk L2YCoE1TwgP8Fp0s

Doebele, A. (2012). Technology and the Choral Art: Music in the Cloud for the Modern Choral Director. The Choral Journal, 53(5), 91-95.

Dourish, P. (2006). Implications for design. Proceedings of the SIGCHI Conference on Human Factors in Computing Systems, 541-550.

Ekerdt, D. J. (1986). The busy ethic: Moral continuity between work and retirement. The Gerontologist, 26(3), 239-244.

Farnham, S. D., \& Churchill, E. F. (2011). Faceted identity, faceted lives: Social and technical issues with being yourself online. Proceedings of the ACM 2011 Conference on Computer Supported Cooperative Work, 359-368. http://dl.acm.org/citation.cfm?id=1958880

Ferrario, M. A., Simm, W., Gradinar, A., Forshaw, S., Smith, M. T., Lee, T., Smith, I., \& Whittle, J. (2017). Computing and mental health: Intentionality and reflection at the click of a button. Proceedings of the 11th EAI International Conference on Pervasive Computing Technologies for Healthcare, 1-10.

Friemel, T. N. (2016). The digital divide has grown old: Determinants of a digital divide among seniors. New Media \& Society, 18(2), 313-331. 
Gibson, D. M. (1987). Interaction and well-being in old age: Is it quantity or quality that counts? The International Journal of Aging and Human Development, 24(1), $29-40$.

Guo, P. J. (2017). Older Adults Learning Computer Programming: Motivations, Frustrations, and Design Opportunities. Proceedings of the 2017 CHI Conference on Human Factors in Computing Systems, 7070-7083. https://doi.org/10.1145/3025453.3025945

Gutierrez, F. J., \& Ochoa, S. F. (2016). Mom, I Do Have a Family!: Attitudes, Agreements, and Expectations on the Interaction with Chilean Older Adults. Proceedings of the 19th ACM Conference on Computer-Supported Cooperative Work \& Social Computing, 1402-1411. https://doi.org/10.1145/2818048.2820000

Hallam, S., Creech, A., Varvarigou, M., \& McQueen, H. (2012). Perceived benefits of active engagement with making music in community settings. International Journal of Community Music, 5(2), 155-174. https://doi.org/10.1386/ijcm.5.2.155_1

Hays, T. (2005). Well-being in later life through music. Australasian Journal on Ageing, 24(1), 28-32.

Hays, T., \& Minichiello, V. (2005). The meaning of music in the lives of older people: A qualitative study. Psychology of Music, 33(4), 437-451.

Hoare, M., Benford, S., Jones, R., \& Milic-Frayling, N. (2014). Coming in from the Margins: Amateur Musicians in the Online Age. Proceedings of the SIGCHI Conference on Human Factors in Computing Systems, 1295-1304. https://doi.org/10.1145/2556288.2557298

Holstein, M., \& Minkler, M. (2007). Critical Gerontology: Reflections for the 21st Century. In Critical perspectives on ageing societies: Vol. Bernard M, ScharfT (pp. 13-26). Policy. https://cam.ldls.org.uk/vdc_100046599504.0x000001

Hope, A., Schwaba, T., \& Piper, A. M. (2014). Understanding Digital and Material Social Communications for Older Adults. Proceedings of the SIGCHI Conference on Human Factors in Computing Systems, 3903-3912. https://doi.org/10.1145/2556288.2557133

Hopkins, N., Reicher, S. D., Khan, S. S., Tewari, S., Srinivasan, N., \& Stevenson, C. (2016). Explaining effervescence: Investigating the relationship between shared social identity and positive experience in crowds. Cognition and Emotion, 30(1), 20-32. https://doi.org/10.1080/02699931.2015.1015969

Hornung, D., Müller, C., Shklovski, I., Jakobi, T., \& Wulf, V. (2017). Navigating Relationships and Boundaries: Concerns Around ICT-uptake for Elderly People. Proceedings of the 2017 CHI Conference on Human Factors in Computing Systems, 7057-7069. https://doi.org/10.1145/3025453.3025859

Kaptelinin, V., \& Bannon, L. J. (2012). Interaction Design Beyond the Product: Creating Technology-Enhanced Activity Spaces. Human-Computer Interaction, 27(3), 277-309. https://doi.org/10.1080/07370024.2011.646930 
Kelly, R., Gooch, D., Patil, B., \& Watts, L. (2017). Demanding by Design: Supporting Effortful Communication Practices in Close Personal Relationships.

Proceedings of the 2017 ACM Conference on Computer Supported Cooperative Work and Social Computing, 70-83. https://doi.org/10.1145/2998181.2998184

Kirk, D. S., \& Sellen, A. (2010). On human remains: Values and practice in the home archiving of cherished objects. ACM Transactions on Computer-Human Interaction (TOCHI), 17(3), 10.

Kobayashi, M., Arita, S., Itoko, T., Saito, S., \& Takagi, H. (2015). Motivating MultiGenerational Crowd Workers in Social-Purpose Work. Proceedings of the 18th ACM Conference on Computer Supported Cooperative Work \& Social Computing, 1813-1824. http://dl.acm.org/citation.cfm?id=2675255

Krause, A. E., \& North, A. C. (2014). Music listening in everyday life: Devices, selection methods, and digital technology. Psychology of Music, 0305735614559065. https://doi.org/10.1177/0305735614559065

Kroger, J., \& McLean, K. C. (2011). Identity Narratives during the Adult Years: Development and Learning. In The Oxford Handbook of Reciprocal Adult Development and Learning (2 ed.) (Carol Hoare). Oxford University Press.

Kuutti, K., \& Bannon, L. J. (2014). The turn to practice in HCI: Towards a research agenda. Proceedings of the SIGCHI Conference on Human Factors in Computing Systems, 3543-3552.

Lang, C., \& Barton, H. (2015). Just untag it: Exploring the management of undesirable Facebook photos. Computers in Human Behavior, 43, 147-155. https://doi.org/10.1016/j.chb.2014.10.051

Lazar, A., Diaz, M., Brewer, R., Kim, C., \& Piper, A. M. (2017). Going Gray, Failure to Hire, and the Ick Factor: Analyzing How Older Bloggers Talk about Ageism. Proceedings of the 2017 ACM Conference on Computer Supported Cooperative Work and Social Computing, 655-668. https://doi.org/10.1145/2998181.2998275

Lazar, A., Edasis, C., \& Piper, A. M. (2017). A Critical Lens on Dementia and Design in HCI. CHI, 2175-2188.

Lazar, A., \& Nguyen, D. H. (2017). Successful Leisure in Independent Living Communities: Understanding Older Adults' Motivations to Engage in Leisure Activities. Proceedings of the 2017 CHI Conference on Human Factors in Computing Systems, 7042-7056. https://doi.org/10.1145/3025453.3025802

Leong, T. W., \& Wright, P. C. (2013). Revisiting Social Practices Surrounding Music. Proceedings of the SIGCHI Conference on Human Factors in Computing Systems, 951-960. https://doi.org/10.1145/2470654.2466122

Liddle, J. L. M., Parkinson, L., \& Sibbritt, D. W. (2013). Purpose and pleasure in late life: Conceptualising older women's participation in art and craft activities. Journal of Aging Studies, 27(4), 330-338. https://doi.org/10.1016/j.jaging.2013.08.002 
Light, A., Howland, K., Hamilton, T., \& Harley, D. A. (2017). The Meaning of Place in Supporting Sociality. Proceedings of the 2017 Conference on Designing Interactive Systems, 1141-1152. https://doi.org/10.1145/3064663.3064728

Lindley, J., Coulton, P., \& Sturdee, M. (2017). Implications for Adoption. Proceedings of the 2017 CHI Conference on Human Factors in Computing Systems, 265277. https://doi.org/10.1145/3025453.3025742

Lindley, S. E. (2015). Making time. Proceedings of the 18th ACM Conference on Computer Supported Cooperative Work \& Social Computing, 1442-1452.

Lindley, S., \& Wallace, J. (2015). Placing in Age: Transitioning to a New Home in Later Life. ACM Transactions on Computer-Human Interaction (TOCHI), 22(4), 20:1-20:39. https://doi.org/10.1145/2755562

Mao, M., Blackwell, A. F., Lukate, J. M., \& Good, D. A. (2016). Supporting Retirement Socially and Musically by Technology: An Ethnographic Study of Local Community Musicians. Proceedings of the 2016 CHI Conference Extended Abstracts on Human Factors in Computing Systems, 2886-2892. http://dl.acm.org/citation.cfm?id=2892285

Markus, H., \& Nurius, P. (1986). Possible selves. American Psychologist, 41(9), 954.

Marwick, A. E., \& Boyd, D. (2011). I tweet honestly, I tweet passionately: Twitter users, context collapse, and the imagined audience. New Media \& Society, 13(1), 114-133. https://doi.org/10.1177/1461444810365313

Massimi, M., Bender, J. L., Witteman, H. O., \& Ahmed, O. H. (2014). Life Transitions and Online Health Communities: Reflecting on Adoption, Use, and Disengagement. Proceedings of the 17th ACM Conference on Computer Supported Cooperative Work \& Social Computing, 1491-1501. https://doi.org/10.1145/2531602.2531622

Massimi, M., Dimond, J. P., \& Le Dantec, C. A. (2012). Finding a New Normal: The Role of Technology in Life Disruptions. Proceedings of the ACM 2012 Conference on Computer Supported Cooperative Work, 719-728. https://doi.org/10.1145/2145204.2145314

McNeill, A. R., Coventry, L., Pywell, J., \& Briggs, P. (2017). Privacy Considerations when Designing Social Network Systems to Support Successful Ageing. Proceedings of the 2017 CHI Conference on Human Factors in Computing Systems, 6425-6437. https://doi.org/10.1145/3025453.3025861

Molapo, M., Densmore, M., \& DeRenzi, B. (2017). Video Consumption Patterns for First Time Smartphone Users: Community Health Workers in Lesotho. Proceedings of the 2017 CHI Conference on Human Factors in Computing Systems, 6159-6170. https://doi.org/10.1145/3025453.3025616

Morreale, F., Moro, G., Chamberlain, A., Benford, S., \& McPherson, A. P. (2017). Building a Maker Community Around an Open Hardware Platform. Proceedings of the 2017 CHI Conference on Human Factors in Computing Systems, 6948-6959. https://doi.org/10.1145/3025453.3026056

Morrissey, K., Garbett, A., Wright, P., Olivier, P., Jenkins, E. I., \& Brittain, K. (2017). Care and Connect: Exploring Dementia-Friendliness Through an Online 
Community Commissioning Platform. Proceedings of the 2017 CHI Conference on Human Factors in Computing Systems, 2163-2174.

https://doi.org/10.1145/3025453.3025732

Morrissey, K., Wood, G., Green, D., Pantidi, N., \& McCarthy, J. (2016). 'I'M a Rambler, I'M a Gambler, I'M a Long Way from Home': The Place of Props, Music, and Design in Dementia Care. Proceedings of the 2016 ACM Conference on Designing Interactive Systems, 1008-1020. https://doi.org/10.1145/2901790.2901798

Müller, C., Hornung, D., Hamm, T., \& Wulf, V. (2015). Measures and tools for supporting ICT appropriation by elderly and non tech-savvy persons in a longterm perspective. ECSCW 2015: Proceedings of the 14th European Conference on Computer Supported Cooperative Work, 19-23 September 2015, Oslo, Norway, 263-281. http://link.springer.com/chapter/10.1007/978-3-319-204994_14

Mun, Y. Y., \& Hwang, Y. (2003). Predicting the use of web-based information systems: Self-efficacy, enjoyment, learning goal orientation, and the technology acceptance model. International Journal of Human-Computer Studies, 59(4), 431-449.

Nippert-Eng, C. (1996). Calendars and keys: The classification of "home" and "work". Sociological Forum, 11(3), 563-582. https://doi.org/10.1007/BF02408393

Odom, W., Banks, R., Kirk, D., Harper, R., Lindley, S., \& Sellen, A. (2012). Technology Heirlooms?: Considerations for Passing Down and Inheriting Digital Materials. Proceedings of the SIGCHI Conference on Human Factors in Computing Systems, 337-346. https://doi.org/10.1145/2207676.2207723

O'Flynn, J. (2015). Strengthening choral community: The interaction of face-to-face and online activities amongst a college choir. International Journal of Community Music, 8(1), 73-92.

Ouwehand, C., de Ridder, D. T. D., \& Bensing, J. M. (2007). A review of successful aging models: Proposing proactive coping as an important additional strategy. Clinical Psychology Review, 27(8), 873-884. https://doi.org/10.1016/j.cpr.2006.11.003

Packer, J., \& Ballantyne, J. (2011). The impact of music festival attendance on young people's psychological and social well-being. Psychology of Music, 39(2), 164181.

Pearce, E., Launay, J., \& Dunbar, R. I. M. (2015). The ice-breaker effect: Singing mediates fast social bonding. Royal Society Open Science, 2(10). https://doi.org/10.1098/rsos.150221

Piper, A. M., Weibel, N., \& Hollan, J. (2013). Audio-enhanced Paper Photos: Encouraging Social Interaction at Age 105. Proceedings of the 2013 Conference on Computer Supported Cooperative Work, 215-224. https://doi.org/10.1145/2441776.2441802 
Reicher, S., \& Hopkins, N. (2016). Perception, Action, and the Social Dynamics of the Variable Self. Psychological Inquiry, 27(4), 341-347. https://doi.org/10.1080/1047840X.2016.1217584

Rice, M., Tan, W. P., Ong, J., Yau, L. J., Wan, M., \& Ng, J. (2013). The Dynamics of Younger and Older Adult's Paired Behavior when Playing an Interactive Silhouette Game. Proceedings of the SIGCHI Conference on Human Factors in Computing Systems, 1081-1090. https://doi.org/10.1145/2470654.2466138

Righi, V., Sayago, S., \& Blat, J. (2017). When we talk about older people in HCI, who are we talking about? Towards a 'turn to community' in the design of technologies for a growing ageing population. International Journal of HumanComputer Studies. https://doi.org/10.1016/j.ijhcs.2017.06.005

Riley, P., Alm, N., \& Newell, A. (2009). An interactive tool to promote musical creativity in people with dementia. Computers in Human Behavior, 25(3), 599608. https://doi.org/10.1016/j.chb.2008.08.014

Rogers, Y., Paay, J., Brereton, M., Vaisutis, K. L., Marsden, G., \& Vetere, F. (2014). Never Too Old: Engaging Retired People Inventing the Future with MaKey MaKey. Proceedings of the SIGCHI Conference on Human Factors in Computing Systems, 3913-3922. https://doi.org/10.1145/2556288.2557184

Rosner, D. (2016). Conflicting Ideologies of the Digital Hand: Locating the Material in a Digital Age. In Critical Craft: Technology, Globalization, and Capitalism (pp. 189-198). Bloomsbury Publishing.

Rozanova, J. (2010). Discourse of successful aging in The Globe \& Mail: Insights from critical gerontology. Journal of Aging Studies, 24(4), 213-222.

Sacks, H. (1992). Lectures on conversation. Blackwell.

Sayago, S., Forbes, P., \& Blat, J. (2012). Older People's Social Sharing Practices in YouTube Through an Ethnographical Lens. Proceedings of the 26th Annual BCS Interaction Specialist Group Conference on People and Computers, 185-194. http://dl.acm.org/citation.cfm?id=2377916.2377937

Sease, R., \& McDonald, D. W. (2009). Musical Fingerprints: Collaboration Around Home Media Collections. Proceedings of the ACM 2009 International Conference on Supporting Group Work, 331-340. https://doi.org/10.1145/1531674.1531724

Seligman, M. E. (2012). Flourish: A visionary new understanding of happiness and well-being. Simon and Schuster.

Shklovski, I., Palen, L., \& Sutton, J. (2008). Finding Community Through Information and Communication Technology in Disaster Response. Proceedings of the 2008 ACM Conference on Computer Supported Cooperative Work, 127-136. https://doi.org/10.1145/1460563.1460584

Shove, E. (2007). The design of everyday life. Berg.

Shove, E., Pantzar, M., \& Watson, M. (2012). The Dynamics of Social Practice: Everyday Life and how it Changes. SAGE. 
Stenner, P., McFarquhar, T., \& Bowling, A. (2011). Older people and 'active ageing':

Subjective aspects of ageing actively. Journal of Health Psychology, 16(3), 467477. https://doi.org/10.1177/1359105310384298

Stephens, C., Alpass, F., Towers, A., \& Stevenson, B. (2011). The Effects of Types of Social Networks, Perceived Social Support, and Loneliness on the Health of Older People: Accounting for the Social Context. Journal of Aging and Health, 23(6), 887-911. https://doi.org/10.1177/0898264311400189

Suchman, L. (2002). Practice-based Design of Information Systems: Notes From the Hyperdeveloped World. The Information Society, 18(2), 139-144.

Suchman, L., Blomberg, J., Orr, J. E., \& Trigg, R. (1999). Reconstructing technologies as social practice. American Behavioral Scientist, 43(3), 392-408.

Sugarhood, P., Eakin, P., \& Summerfield-Mann, L. (2017). Participation in advanced age: Enacting values, an adaptive process. Ageing \&amp; Society, 37(8), 16541680. https://doi.org/10.1017/S0144686X16000568

Sun, Y., Lindtner, S., Ding, X., Lu, T., \& Gu, N. (2015). Reliving the Past \& Making a Harmonious Society Today: A Study of Elderly Electronic Hackers in China. Proceedings of the 18th ACM Conference on Computer Supported Cooperative Work \& Social Computing, 44-55.

Tajfel, H. (2010). Social identity and intergroup relations. Cambridge University Press.

Tajfel, H., \& Turner, J. C. (2004). The social identity theory of intergroup behavior.

Taylor, N., Clarke, L., \& Gorkovenko, K. (2017). Community Inventor Days:

Scaffolding Grassroots Innovation with Maker Events. Proceedings of the 2017 Conference on Designing Interactive Systems, 1201-1212. https://doi.org/10.1145/3064663.3064723

Taylor, N., Hurley, U., \& Connolly, P. (2016). Making Community: The Wider Role of Makerspaces in Public Life. Proceedings of the 2016 CHI Conference on Human Factors in Computing Systems, 1415-1425. https://doi.org/10.1145/2858036.2858073

Thomas, L., Briggs, P., Hart, A., \& Kerrigan, F. (2017). Understanding social media and identity work in young people transitioning to university. Computers in Human Behavior, 76, 541-553. https://doi.org/10.1016/j.chb.2017.08.021

Turner, J. C., Hogg, M. A., Oakes, P. J., Reicher, S. D., \& Wetherell, M. S. (1987). Rediscovering the social group: A self-categorization theory. Basil Blackwell.

Vines, J., Blythe, M., Dunphy, P., Vlachokyriakos, V., Teece, I., Monk, A., \& Olivier, P. (2012). Cheque Mates: Participatory Design of Digital Payments with Eighty Somethings. Proceedings of the SIGCHI Conference on Human Factors in Computing Systems, 1189-1198. https://doi.org/10.1145/2207676.2208569

Vines, J., Pritchard, G., Wright, P., Olivier, P., \& Brittain, K. (2015). An Age-Old Problem: Examining the Discourses of Ageing in HCI and Strategies for Future Research. ACM Transactions on Computer-Human Interaction (TOCHI), 22(1), 2.

Voida, S., Edwards, W. K., Newman, M. W., Grinter, R. E., \& Ducheneaut, N. (2006). Share and Share Alike: Exploring the User Interface Affordances of File 
Sharing. Proceedings of the SIGCHI Conference on Human Factors in Computing Systems, 221-230. https://doi.org/10.1145/1124772.1124806

Walker, A. (2002). A strategy for active ageing. International Social Security Review, 55(1), 121-139. https://doi.org/10.1111/1468-246X.00118

Wang, X., Knearem, T., Gui, F., Gupta, S., Zhu, H., Williams, M., \& Carroll, J. (2018). The Safety Net of Aging in Place: Understanding How Older Adults Construct, Develop, and Maintain Their Social Circles. Proceedings of the 12th EAI International Conference on Pervasive Computing Technologies for Healthcare. PervasiveHealth' 18.

World Health Organization. (2002). Active Aging-A Policy Framework. World Health Organisation. http://www.who.int/ageing/publications/active_ageing/en/

Wulf, V., Müller, C., Pipek, V., Randall, D., Rohde, M., \& Stevens, G. (2015). PracticeBased Computing: Empirically Grounded Conceptualizations Derived from Design Case Studies. In V. Wulf, K. Schmidt, \& D. Randall (Eds.), Designing Socially Embedded Technologies in the Real-World (pp. 111-150). Springer. https://doi.org/10.1007/978-1-4471-6720-4_7

Yuan, C. W., Kropczynski, J., Wirth, R., Rosson, M. B., \& Carroll, J. M. (2017). Investigating Older Adults' Social Networks and Coproduction Activities for Health. Proceedings of the 11th EAI International Conference on Pervasive Computing Technologies for Healthcare, 68-77. https://doi.org/10.1145/3154862.3154876 